\title{
Dynamic genome-wide association analysis and identification of candidate genes involved in anaerobic germination tolerance in rice
}

Ling Su, Jing Yang, Dandan Li, Ziai Peng, Aoyun Xia, Meng Yang, Lixin Luo, Cuihong Huang, Jiafeng Wang, Hui Wang, Zhiqiang Chen and Tao Guo* (D)

\begin{abstract}
Background: In Asian rice production, an increasing number of countries now choose the direct seeding mode because of rising costs, labour shortages and water shortages. The ability of rice seeds to undergo anaerobic germination (AG) plays an important role in the success of direct seeding.

Results: In this study, we used 2,123,725 single nucleotide polymorphism (SNP) markers based on resequencing to conduct a dynamic genome-wide association study (GWAS) of coleoptile length (CL) and coleoptile diameter (CD) in 209 natural rice populations. A total of 26 SNP loci were detected in these two phenotypes, of which 5 overlapped with previously reported loci (S1_ 39674301, S6_ 20797781, S7_ 18722403, S8_9946213, S11_ 19165397), and two sites were detected repeatedly at different time points (S3_ 24689629 and S5_ 27918754). We suggest that these 7 loci $\left(-\log _{10}(P)\right.$ value $\left.>7.3271\right)$ are the key sites that affect AG tolerance. To screen the candidate genes more effectively, we sequenced the transcriptome of the flooding-tolerant variety R151 in six key stages, including anaerobic (AN) and the oxygen conversion point (AN-A), and obtained high-quality differential expression profiles. Four reliable candidate genes were identified: Os01g0911700 (OsVP1), Os05g0560900 (OsGA20x8), Os05g0562200 (OsDi19-1) and Os06g0548200. Then qRT-PCR and LC-MS/ MS targeting metabolite detection technology were used to further verify that the up-regulated expression of these four candidate genes was closely related to $A G$.
\end{abstract}

Conclusion: The four novel candidate genes were associated with gibberellin (GA) and abscisic acid (ABA) regulation and cell wall metabolism under oxygen-deficiency conditions and promoted coleoptile elongation while avoiding adverse effects, allowing the coleoptile to obtain oxygen, escape the low-oxygen environment and germinate rapidly. The results of this study improve our understanding of the genetic basis of AG in rice seeds, which is conducive to the selection of flooding-tolerant varieties suitable for direct seeding.

Keywords: Rice, Anaerobic germination tolerance, Coleoptile, Dynamic GWAS, RNA-seq, Candidate gene

\footnotetext{
* Correspondence: guo.tao@vip.163.com

National Engineering Research Center of Plant Space Breeding, South China

Agricultural University, Guangzhou 510642, China
}

\section{Springer Open}

(c) The Author(s). 2021 Open Access This article is licensed under a Creative Commons Attribution 4.0 International License, which permits use, sharing, adaptation, distribution and reproduction in any medium or format, as long as you give appropriate credit to the original author(s) and the source, provide a link to the Creative Commons licence, and indicate if changes were made. The images or other third party material in this article are included in the article's Creative Commons licence, unless indicated otherwise in a credit line to the material. If material is not included in the article's Creative Commons licence and your intended use is not permitted by statutory regulation or exceeds the permitted use, you will need to obtain permission directly from the copyright holder. To view a copy of this licence, visit http://creativecommons.org/licenses/by/4.0/. 


\section{Background}

Cultivated rice (Oryza sativa L.) is a staple food for over half of the world's population (Zhang et al. 2019). The world's rice demand is projected to increase by $25 \%$ from 2001 to 2025 with a targeted production of 732.5 MT, which is achievable by the addition of 5.9 MT every year. However, based on population growth, the Food and Agricultural Organization estimates that by 2050, the world rice requirement will be 524 MT with an annual increase of $2 \mathrm{MT}$ from the present level of production (Jeon et al. 2011).

Worldwide, irrigated rice ecosystems comprise 55\% of the world's rice-growing area and provide $75 \%$ of global rice production (Mahender et al. 2015). However, the current evidence shows a decline in grain yield productivity due to looming threats to natural resources, falling water tables, mounting labour shortages, energy scarcity, increasing input prices and changing climatic conditions (Singh et al. 2013). However, the water-, energy-, and labour-intensive system of transplanted puddled rice is steadily being replaced by direct-seeded rice (DSR) due to the progressive scarcity of these resources (Miro et al. 2017).

DSR can be classified as wet DSR, dry DSR, or water DSR (Mahender et al. 2015). Compared with wet and dry DSR, water DSR (whereby seeds are broadcast into standing water) is more advantageous because it is less labour and time intensive and restrains weed growth (Yamauchi et al. 1993). However, rice is extremely sensitive to anoxia during germination and early seedling growth (Yamauchi et al. 1993; Ismail et al. 2009; Yang et al. 2019b). In the case of heavy rainfall during the germination of direct-seeded rice, standing water on the soil surface will significantly affect the seedling rate and thus affect yield (Magneschi et al. 2009). The rice coleoptile is one of the few plant tissues that can grow under hypoxic conditions (Pearce and Jackson 1991). Anoxia promotes coleoptile elongation and inhibits the growth of young stems and roots (Fred et al. 1981). Under anaerobic conditions, the coleoptile elongates rapidly, breaks through the water surface and transports oxygen to the underwater tissues (Alpi and Beevers 1983). The coleoptile elongates rapidly to reach the aerobic environment, providing nutrients for the primary leaves and roots and then promoting seedling morphogenesis. Therefore, it is of great significance to explore the mechanism of rice anaerobic germination (AG) tolerance and the morphological and physiological responses of the coleoptile in anaerobic environments to promote the development of rice direct seeding technology.

When rice is in an anaerobic environment, its coleoptile elongation varies widely among different varieties as a typical quantitative characteristic (Perata and Alpi 1993; Magneschi et al. 2009; Magneschi and Perata 2009). To determine the genetic basis of this phenomenon, in recent years, quantitative trait loci (QTLs) have been used to identify different populations, and some QTLs related to coleoptile elongation have been found. Angaji (2008) reported four putative QTLs on chromosomes $1,2,11$, and 12 in a $\mathrm{BC}_{2} \mathrm{~F}_{2}$ population derived from the cross of KHAIYAN and IR64. These QTLs explained $51.4 \%$ of the phenotypic variance. Similarly, Khao Hlan On, a anoxia-tolerant accession, was crossed with IR64 to construct $\mathrm{BC}_{2} \mathrm{~F}_{2}$ lines, and five QTLs were found on chromosomes 1, 3, 7, and 9 (Angaji et al. 2009). Among them, TPP7 (Kretzschmar et al. 2015) was found in $q A G$ 9-2 (Angaji et al. 2010) and shown to participate in trehalose-6-phosphate metabolism, enhance starch mobilization, and improve AG tolerance. Offspring with the tolerance allele showed a high germination rate, as their seedlings could reach the water surface (Angaji et al. 2010). Septiningsih et al. (2013) used 118 simple sequence repeat (SSR) molecular markers and an $\mathrm{F}_{2: 3}$ population constructed from IR42 and Ma-Zhan Red to detect 6 QTLs related to seed germination and flooding tolerance under $10 \mathrm{~cm}$ flooding stress, and the $\mathrm{BC}_{2} \mathrm{~F}_{3}$ generation was used to verify the major effect locus $q A G 7.1$ on chromosome 7 and estimate its contribution rate at $31.7 \%$. Lee et al. (2017) used backcross inbred lines (BILs) of Kasalath and Nipponbare to evaluate deep sowing ( $5 \mathrm{~cm}$ sowing depth) performance. With coleoptile length (CL) as an indicator, a QTL location assay identified sites that affected coleoptile elongation on chromosomes 3 and 5, and these sites explained phenotypic variations of $11.8 \%$ and $12.0 \%$, respectively (Lee et al. 2017). Yang et al. (2019a, 2019b) used linkage analysis of 192 recombinant inbred lines (RILs) produced from YZX and 02428 to detect 13 stable QTLs on chromosomes 1, 2, 3, 4, 6, 7, 9, 10 and 12 , taking the $\mathrm{CL}$, coleoptile diameter $(\mathrm{CD})$, coleoptile surface area (CSA) and coleoptile volume (CV) at 6 days after submergence and the germination of the seeds of the two generations as indicators.

Most of the existing reports are based on the genetic site mining of populations derived from different parents (such as RILs; NILs; and BILs), but these studies are limited by the genetic information possessed by the parents and by molecular marker density, so their identification of flooding-resistant germination loci related to coleoptile elongation is limited.

Genome-wide association studies (GWAS) based on SSR (Li et al. 2012) or single nucleotide polymorphism (SNP) markers (Huang et al. 2010; Zhao et al. 2011; Huang et al. 2012) have been widely used in model plants, including rice. By identifying high-density SNPs in different germplasm accessions based on second- 
generation genome sequencing or SNP array approaches, we can obtain a very high resolution (Chen et al. 2014; Yu et al. 2014; Wu et al. 2015), which provides a strong advantage for the mining of complex QTLs. Hsu and Tung (2015) analysed the association of 153 indica, japonica and Australian rice populations by using genome-wide association technology and found that 88 significant SNPs were correlated with the anaerobic response index based on differences in CL between control and submerged rice plants. Among them, only one unique QTL on the long arm of chromosome 1 showed a strong signal in a RIL population from Nipponbare/ IR64 hybridization, and this QTL explained approximately $27 \%$ of the phenotypic variation (Hsu and Tung 2015). The study revealed that the HXK6 gene was located in this genomic region. HXK6 is a double-target mitochondrial and nuclear protein (Cho et al. 2009; Huang et al. 2009). As a glucose sensor (Cho et al. 2009; Granot et al. 2013; Granot et al. 2014), it may be involved in hexose phosphorylation to regulate the expression of important hypoxia-inducible genes, such as CIPK15 and alcohol dehydrogenase (Yim et al. 2012; Lim et al. 2013; Shingaki-Wells et al. 2014), and therefore improve the survival rate of rice seedlings during submerged germination.

Zhang et al. (2017) carried out GWAS analysis using a mixed linear model with 432 indica rice varieties in normal and flooded environments and detected 11 and 9 significant SNPs for flooded coleoptile length (FCL) and flood tolerance index (FTI). Haplotype analysis found that LOC_Os06g03520 contained a protein DUF domain similar to that in genes involved in the energy metabolism pathway (OsTPP7 and OsCIPK15) and was a highly anoxia-induced candidate gene. Nghi et al. (2019) conducted a GWAS on 273 japonica rice materials to find new chromosomal regions related to the ability of rice coleoptiles to elongate under flooding conditions. Eleven significant SNPs were found, and 21 candidate genes related to CL were identified.

Coleoptile elongation is the only organic response of rice to anaerobic stress and a reliable characteristic used to study the flooding tolerance of rice genotypes (Setter and Ella 1994; Kato-Noguchi and Morokuma 2007; Zhang et al. 2017). The ongoing improvements of genome sequencing technology will significantly improve the efficiency of GWAS technology in genetic locus identification by allowing researchers to obtain highdensity SNPs by sequencing. In this study, phenotypic data (CL and CD) and 2,123,725 SNP markers were used to perform a dynamic GWAS. The purpose of this study was to detect genetic loci significantly associated with AG in rice, to explore favourable SNP alleles that may be used to breed rice suitable for direct seeding and to find reliable candidate genes to lay a foundation for future study of the molecular mechanism of AG in rice.

\section{Results \\ Statistical Analysis of Phenotypic Variation in Anaerobic Germination Tolerance}

A total of 209 indica and japonica rice accessions from all over the world (Table S1) were tested for anaerobic germination. $\mathrm{CL}, \mathrm{CD}, \mathrm{CSA}$ and $\mathrm{CV}$ on the second, third and fourth days of germination were used as the indexes of submergence tolerance. Abundant genetic variation was detected in this indica and japonica rice accession population (Fig. 1, Table S2). Analysis of variance showed that the 209 rice accessions had significant differences in submerged coleoptile phenotype at different time points. At the same time, both genotype and length of submergence time had significant influences on coleoptile phenotype (Table 1). The variation coefficients of CL, CSA and CV were greater than $10 \%$ on the $2 \mathrm{nd}$, 3rd and 4th days of submergence, indicating that the CL, CSA and CV of the different varieties were significantly different. The variation coefficients of CL, CD, CSA and CV were the greatest on the second day of submerging. With increasing submerging time, the variation coefficients of each phenotype decreased gradually, indicating that the differences in each phenotype were significant on the second day of submerging, and the coleoptiles grew rapidly to avoid the anaerobic environment.

It can be seen from the histogram of frequency distribution (Fig. 2) that after 4 days of continuous oxygendeficiency treatment, the AG tolerance indexes were consistent with a normal distribution (except $\mathrm{CV}$ at 2 and 4 days of submergence), indicating that these traits are regulated by many genes with small effects.

\section{Correlation Analysis of Phenotypic Traits}

Correlation analysis showed correlations among the coleoptile phenotypes after 2 days, 3 days and 4 days of submergence stress (Table 2). Among them, CV-AN2d/CL-AN2d and CSA-AN2d/CSA-AN3d/CSA-AN4d/CD-AN2d/CDAN3d were correlated, but there was no correlation between CV-AN4d and CD-AN2d. CV-AN2d was negatively correlated with CL-AN3d, CL-AN4d, CD-AN4d, CVAN3d and CV-AN4d. CL-AN3d/CSA-AN3d/CV-AN3d, CL-AN4d/CSA-AN4d, and CSA-AN3d/CV-AN3d had very significant positive correlations with a $P$-value $>0.800$.

The dynamic test results of coleoptile phenotypes showed significant correlations among CL and CD measurements at various time points, and these traits play key roles in seed tolerance of anaerobic conditions. This conclusion was also supported by previous work. Therefore, GWAS analysis was performed with $\mathrm{CL}$ and $\mathrm{CD}$ as phenotypes. 


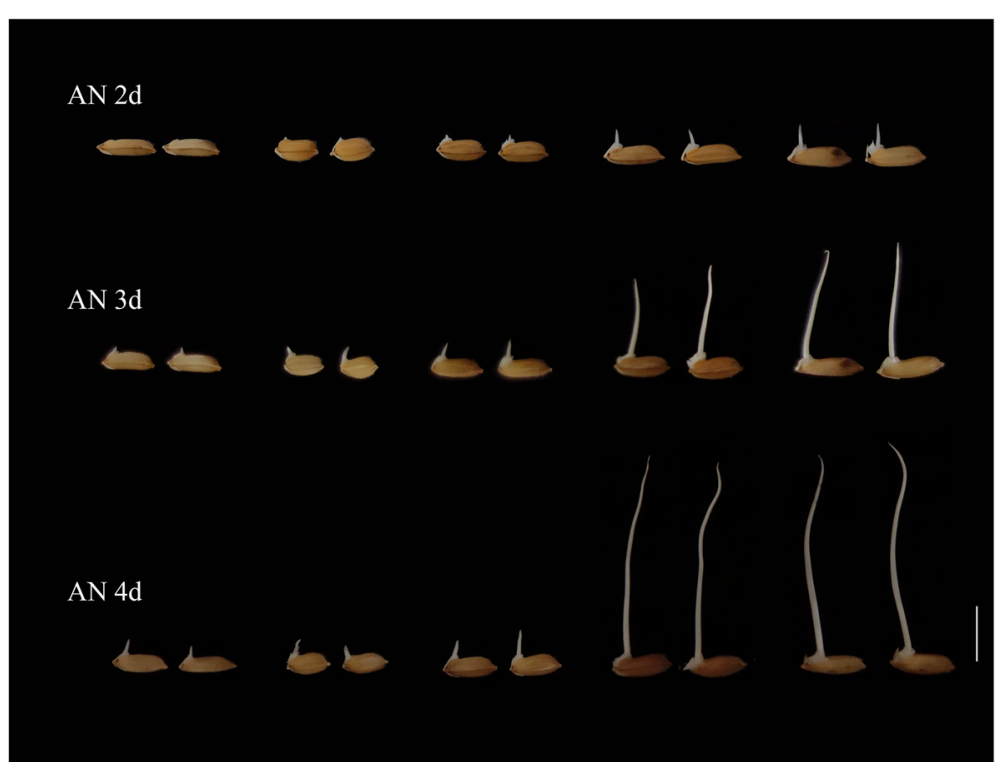

Fig. 1 Phenotypic variation of coleoptile in different rice germplasm at different submerging time points. AN is for anaerobic environment. Scale $=1 \mathrm{~cm}$

\section{Whole-Genome Resequencing and Polymorphism Identification}

In this study, the genomes of 209 rice germplasm accessions were resequenced. Burrows-Wheeler Aligner (BWA) software was used to compare the sequencing data with the reference genome IRGSP-1.0 (Kawahara et al. 2013). Finally, 1243.37 Gbp of clean data was obtained, and the Q30 reached $93.15 \%$. The average contrast ratio between each sample and the reference genome was $93.06 \%$, the average sequencing depth was $12 \times$, and the average coverage of the reference genome was $90.90 \%$ (at least one base coverage).
A total of 2,123,725 SNP sites were detected in this dataset. Among them, the SNP types were mainly C:G > T:A and T:A > C:G (Fig. S1a). Using SnpEff software to annotate the detected SNPs, we found 663,818 SNPs with synonymous mutations and 712,374 with nonsynonymous mutations (Fig. S1b).

\section{Population Genetics and Evolutionary Analysis} Phylogenetic and Population Structure Analysis

From the phylogenetic tree (Fig. 3a), it can be seen that the population structure used in this experiment is uniform, without strong population stratification. Based on

Table 1 Phenotypic variation of rice coleoptile during submergence germination

\begin{tabular}{|c|c|c|c|c|c|}
\hline Phenotype & Environment & Mean \pm SE & Range & $\begin{array}{l}\text { Coefficient of } \\
\text { variation (\%) }\end{array}$ & $P \times E$ \\
\hline \multirow[t]{3}{*}{$\mathrm{CL}$} & AN2d & $0.2226 \pm 0.0132 \mathrm{~cm}$ & $0.0062 \sim 0.6463 \mathrm{~cm}$ & 18.7571 & $* * * a$ \\
\hline & AN3d & $0.6629 \pm 0.0258 \mathrm{~cm}$ & $0.0334 \sim 1.7719 \mathrm{~cm}$ & 13.0543 & \\
\hline & AN4d & $1.2068 \pm 0.0498 \mathrm{~cm}$ & $0.1659 \sim 3.8798 \mathrm{~cm}$ & 12.9767 & \\
\hline \multirow[t]{3}{*}{ CSA } & AN2d & $0.0266 \pm 0.0051 \mathrm{~cm}^{2}$ & $0.0045 \sim 0.6463 \mathrm{~cm}^{2}$ & 56.1438 & \\
\hline & AN3d & $0.1104 \pm 0.0048 \mathrm{~cm}^{2}$ & $0.0098 \sim 0.3259 \mathrm{~cm}^{2}$ & 14.3195 & \\
\hline & AN4d & $0.2030 \pm 0.0089 \mathrm{~cm}^{2}$ & $0.0201 \sim 0.7689 \mathrm{~cm}^{2}$ & 13.7986 & \\
\hline \multirow[t]{3}{*}{$C D$} & AN2d & $0.4543 \pm 0.0272 \mathrm{~mm}$ & $0.1092 \sim 0.6597 \mathrm{~mm}$ & 22.4859 & \\
\hline & AN3d & $0.5155 \pm 0.0137 \mathrm{~mm}$ & $0.3908 \sim 0.6837 \mathrm{~mm}$ & 7.9094 & \\
\hline & AN4d & $0.5496 \pm 0.0065 \mathrm{~mm}$ & $0.4452 \sim 1.0680 \mathrm{~mm}$ & 3.5583 & \\
\hline \multirow[t]{3}{*}{ CV } & AN2d & $0.0008 \pm 0.0001 \mathrm{~cm}^{3}$ & $0.0001 \sim 0.0625 \mathrm{~cm}^{3}$ & 35.6686 & \\
\hline & AN3d & $0.0015 \pm 0.0001 \mathrm{~cm}^{3}$ & $0.0049 \sim 0.0015 \mathrm{~cm}^{3}$ & 18.3201 & \\
\hline & AN4d & $0.0030 \pm 0.0010 \mathrm{~cm}^{3}$ & $0.0003 \sim 0.0419 \mathrm{~cm}^{3}$ & 20.8486 & \\
\hline
\end{tabular}

$\mathrm{a} *$ *** indicates a significant correlation between phenotype and environment treatment. 

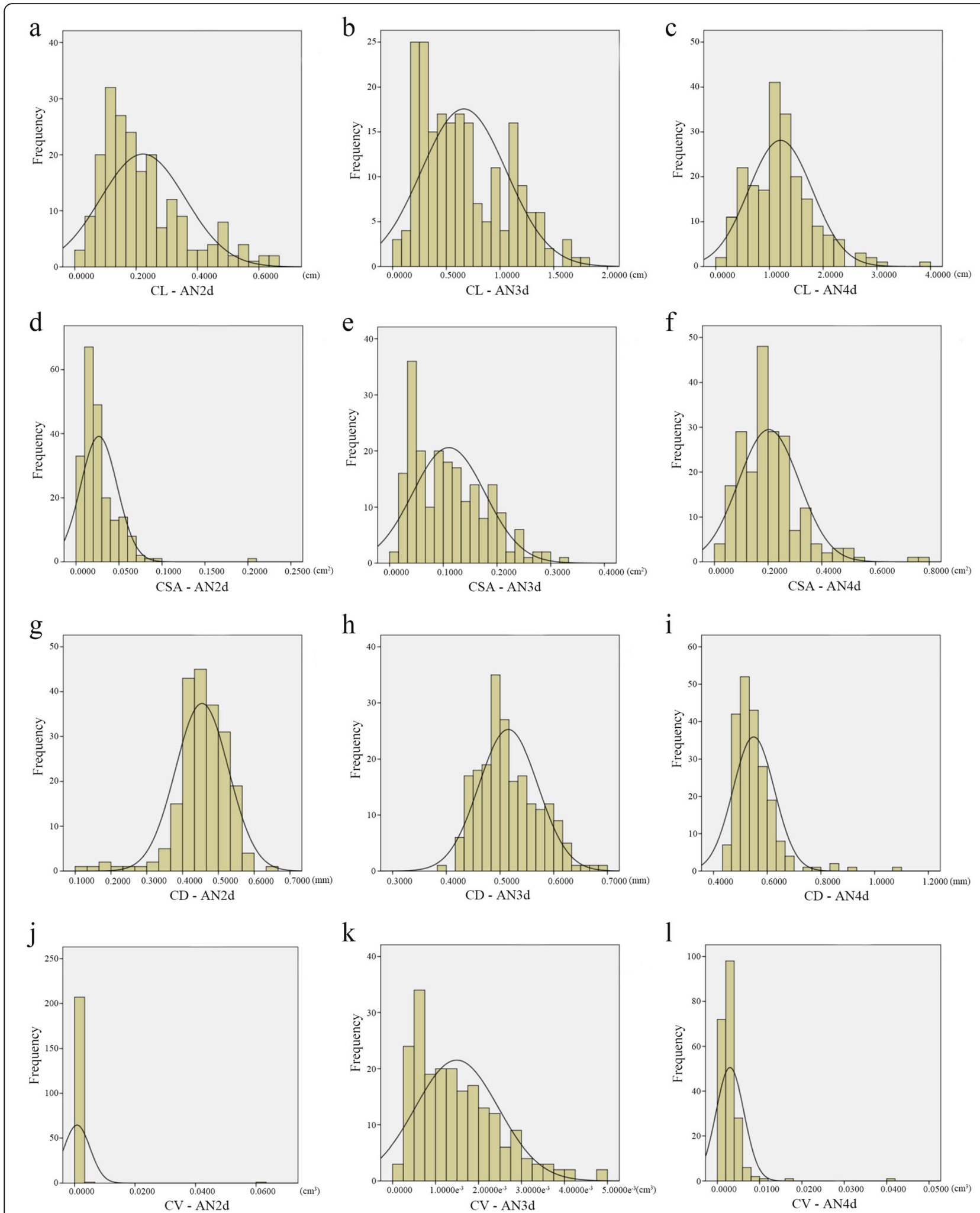

Fig. 2 Frequency distribution histogram of each phenotype of coleoptile at different submergence time points. Note: CL, coleoptile length; CSA, coleoptile surface area; CD, coleoptile diameter; CV, coleoptile volume 
Table 2 Correlation analysis of coleoptile phenotpye

\begin{tabular}{|c|c|c|c|c|c|c|c|c|c|c|c|c|}
\hline Trait & $\begin{array}{l}\mathrm{CL}- \\
\text { AN2d }\end{array}$ & $\begin{array}{l}\text { CL - } \\
\text { AN3d }\end{array}$ & $\begin{array}{l}\text { CL - } \\
\text { AN4d }\end{array}$ & $\begin{array}{l}\text { CSA } \\
\text {-AN2d }\end{array}$ & $\begin{array}{l}\text { CSA - } \\
\text { AN3d }\end{array}$ & $\begin{array}{l}\text { CSA - } \\
\text { AN4d }\end{array}$ & $\begin{array}{l}C D- \\
\text { AN2d }\end{array}$ & $\begin{array}{l}\text { CD - } \\
\text { AN3d }\end{array}$ & $\begin{array}{l}\text { CD - } \\
\text { AN4d }\end{array}$ & $\begin{array}{l}\text { CV - } \\
\text { AN2d }\end{array}$ & $\begin{array}{l}\text { CV - } \\
\text { AN3d }\end{array}$ & $\begin{array}{l}\text { CV- } \\
\text { AN4d }\end{array}$ \\
\hline $\begin{array}{l}C L- \\
\text { AN2d }\end{array}$ & 1 & & & & & & & & & & & \\
\hline $\begin{array}{l}C L- \\
\text { AN3d }\end{array}$ & $0.521^{a}$ & 1 & & & & & & & & & & \\
\hline $\begin{array}{l}\mathrm{CL}- \\
\text { AN4d }\end{array}$ & $0.475^{\mathrm{a}}$ & $0.739^{a}$ & 1 & & & & & & & & & \\
\hline $\begin{array}{l}\text { CSA } \\
- \text { AN2d }\end{array}$ & $0.767^{\mathrm{a}}$ & $0.442^{a}$ & $0.405^{\mathrm{a}}$ & 1 & & & & & & & & \\
\hline $\begin{array}{l}\text { CSA - } \\
\text { AN3d }\end{array}$ & $0.567^{\mathrm{a}}$ & $0.948^{a}$ & $0.725^{a}$ & $0.385^{a}$ & 1 & & & & & & & \\
\hline $\begin{array}{l}\text { CSA - } \\
\text { AN4d }\end{array}$ & $0.445^{a}$ & $0.657^{a}$ & $0.912^{a}$ & $0.403^{a}$ & $0.668^{a}$ & 1 & & & & & & \\
\hline $\begin{array}{l}\text { CD - } \\
\text { AN2d }\end{array}$ & $0.290^{a}$ & $0.268^{a}$ & $0.291^{\mathrm{a}}$ & $0.304^{a}$ & $0.353^{a}$ & $0.250^{a}$ & 1 & & & & & \\
\hline $\begin{array}{l}C D- \\
\text { AN3d }\end{array}$ & $0.215^{a}$ & $0.180^{\mathrm{a}}$ & $0.189^{a}$ & $0.266^{a}$ & $0.313^{a}$ & $0.293^{a}$ & $0.632^{a}$ & 1 & & & & \\
\hline $\begin{array}{l}\text { CD - } \\
\text { AN4d }\end{array}$ & $0.226^{\mathrm{a}}$ & $0.148^{b}$ & $0.181^{a}$ & $0.435^{a}$ & $0.195^{\mathrm{a}}$ & $0.272^{a}$ & $0.404^{a}$ & $.729^{a}$ & 1 & & & \\
\hline $\begin{array}{l}\text { CV - } \\
\text { AN2d }\end{array}$ & 0.066 & -0.034 & -0.023 & 0.128 & 0.042 & 0.002 & 0.054 & 0.005 & -0.01 & 1 & & \\
\hline $\begin{array}{l}\text { CV - } \\
\text { AN3d }\end{array}$ & $0.549^{a}$ & $0.885^{a}$ & $0.710^{a}$ & $0.463^{\mathrm{a}}$ & $0.924^{a}$ & $0.687^{\mathrm{a}}$ & $0.394^{a}$ & $0.452^{a}$ & $0.354^{a}$ & -0.032 & 1 & \\
\hline CV- AN4d & $0.217^{\mathrm{a}}$ & $0.296^{\mathrm{a}}$ & $0.436^{\mathrm{a}}$ & $0.205^{a}$ & $0.324^{a}$ & $0.730^{a}$ & 0.01 & $0.204^{\mathrm{a}}$ & $0.175^{b}$ & -0.016 & $0.409^{a}$ & 1 \\
\hline
\end{tabular}

${ }^{\mathrm{a} A t} 0.01$ level (2-tailed), the correlation was significant

${ }^{\mathrm{b}}$ At 0.05 level (2-tailed), the correlation was significant

the SNPs, Admixture (Alexander et al. 2009) software was used to analyse the group structure of the research materials. Cross-validation error analysis showed that the error peak was lowest at $\mathrm{K}=5$, indicating the optimal grouping (Fig. 3c). The population structure analysis showed no obvious pedigree differentiation in the selected plant materials, confirming that they were suitable for subsequent GWAS analysis. The phylogenetic tree results showed that the selected population could be divided into 5 subgroups, which verified the conclusion that $K=5$ was the optimal result in the population structure analysis. The $\mathrm{Q}$ matrix with $\mathrm{K}=5$ was selected for the subsequent association analysis (Fig. 3d).

Based on the SNP data, EIGENSOFT software was used to perform principal component analysis (PCA) (Price et al. 2006) to cluster the samples (Fig. 3b). The results of PCA supported the evolutionary analysis, further confirming that the degree of discreteness of individual kinship in the population was small.

Dynamic Genome-Wide Association Analysis of Coleoptile Phenotypic Traits under Submergence

Based on the developed high-density SNP marker data, we performed a GWAS on the dynamic changes in two phenotypic traits, $C L$ and $C D$, to mine new genetic loci associated with AG. The Manhattan plots and quantile- quantile (QQ) plots are shown in Figs. 4 and 5. Taking $-\log _{10}(P)$ value $>7.3271$ as the threshold, CL was not associated with GWAS sites under AN2d condition; CD was associated with 23 GWAS sites, including 29 SNPs with extremely significant correlation. Under AN3d condition, CL is associated with one GWAS site, which contains one extremely significant SNP, namely S3 24689629. CD is associated with one GWAS site and contains 7 SNPs that are significantly related. Under AN4d condition, CL was associated with 2 GWAS site, including 3 SNPs with extremely significant correlation. $\mathrm{CD}$ is associated with 16 GWAS site, including 146 SNPs that are significantly correlated (Table S9). According to the values of LD, carefully consider the SNPs in the same area of LD detected after we finalized the 22 significant SNPs associated with CD (8 at AN2d, 1 at AN3d, and 14 at AN4d) and were distributed on chromosomes 1, 2, 3, 5, 6, 7, 8, and 11. Two SNPs were significantly correlated with CL (0 at AN2d, 1 at AN3d, and 2 at AN4d), and they were distributed on chromosomes 1 and 3 (Table 3 ).

To verify the accuracy of our results, we compared them with previously reported QTLs (Jiang et al. 2006; Yang et al. 2019a, 2019b) related to the control of coleoptile elongation and the survival rate of plants under flooding conditions (Angaji et al. 2010; Baltazar et al. 

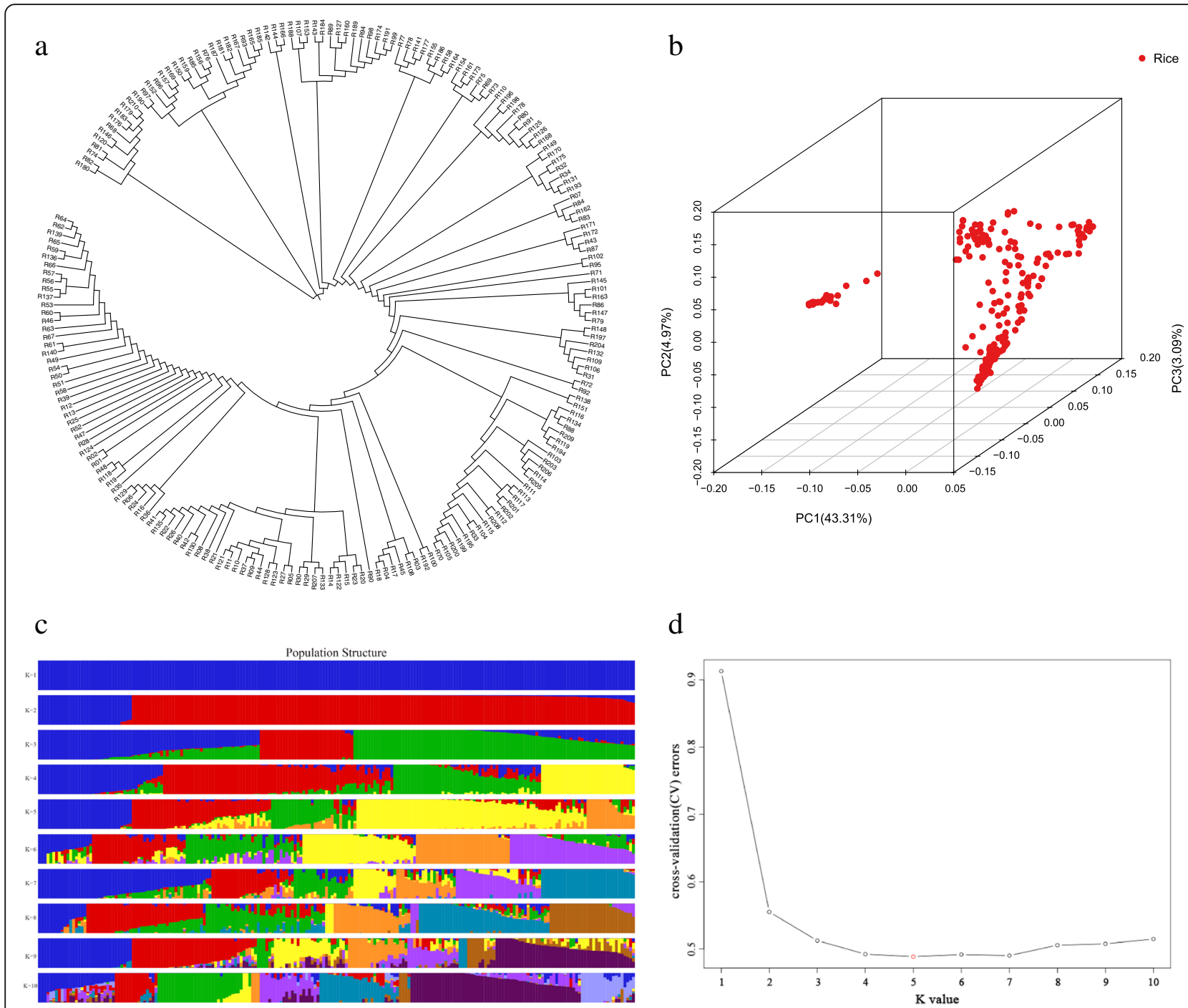

d

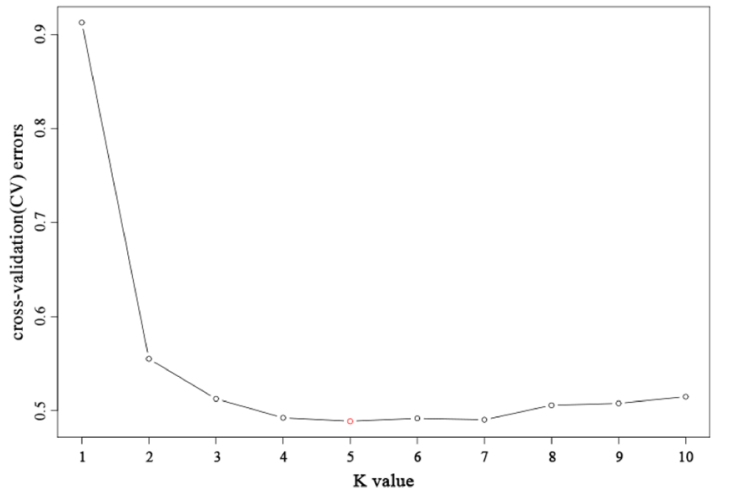

Fig. 3 Genetic evolution of natural populations of indica and japonica rice. a Phylogenetic tree, each branch is a rice germplasm. b Principal component analysis on 2.12 million SNPs of 209 rice accession. PC 1 and PC 2 refer to the first and second principal components, respectively. The numbers in parentheses refer to the proportion of variance explained by the corresponding axes. Red points represent each variety in 209 rice accession. Each point represented a rice germplasm accession. The closer the distance between the points, the closer the relationship was. $\mathbf{c}$ Cluster analysis results of population genotypes, in which each color represents a group and each row represents a group value. $\mathbf{d}$ Cross validation error rate for each $\mathrm{k}$ value. Among them, $\mathrm{K}$ is the smallest when $\mathrm{k}$ is 5

2014; Septiningsih et al. 2013). We found that some of our QTLs has been identified before in rice submerged germination tolerance. We found that 6 genomic regions were colocalized (grey and orange blocks in Fig. 6). A SNP on chromosome 1 (S1_ 39674301), which was significantly associated with $\mathrm{CD}$ in this study, was located in the $q C D-1(\mathrm{ES})$ gene interval reported by Yang et al. (2019a, 2019b) as closely related to CD during the early cropping season. One SNP (S6_20797781) located on chromosome 6 was very close to a gene locus detected in another association study (Hsu and Tung 2015). The physical distance between these two SNPs was only approximately $4 \mathrm{~kb}$. Another SNP (S7_18722403) significantly correlated with $\mathrm{CD}$ at AN4d was found inside the genomic interval of $q A G 7.2$ on chromosome 7; this locus was previously detected using linkage mapping and association mapping (Septiningsih et al. 2013; Hsu and Tung 2015), validating its genetic effect. On chromosome 8 , a SNP (S8_ 9946213) significantly associated with CD was very close to a site detected in another related study as closely related to the anaerobic response index (treated CL vs. control CL; Hsu and Tung 2015), and the physical distance between them was approximately 95 kb. On chromosome 11, another SNP (S11_ 19165397) 


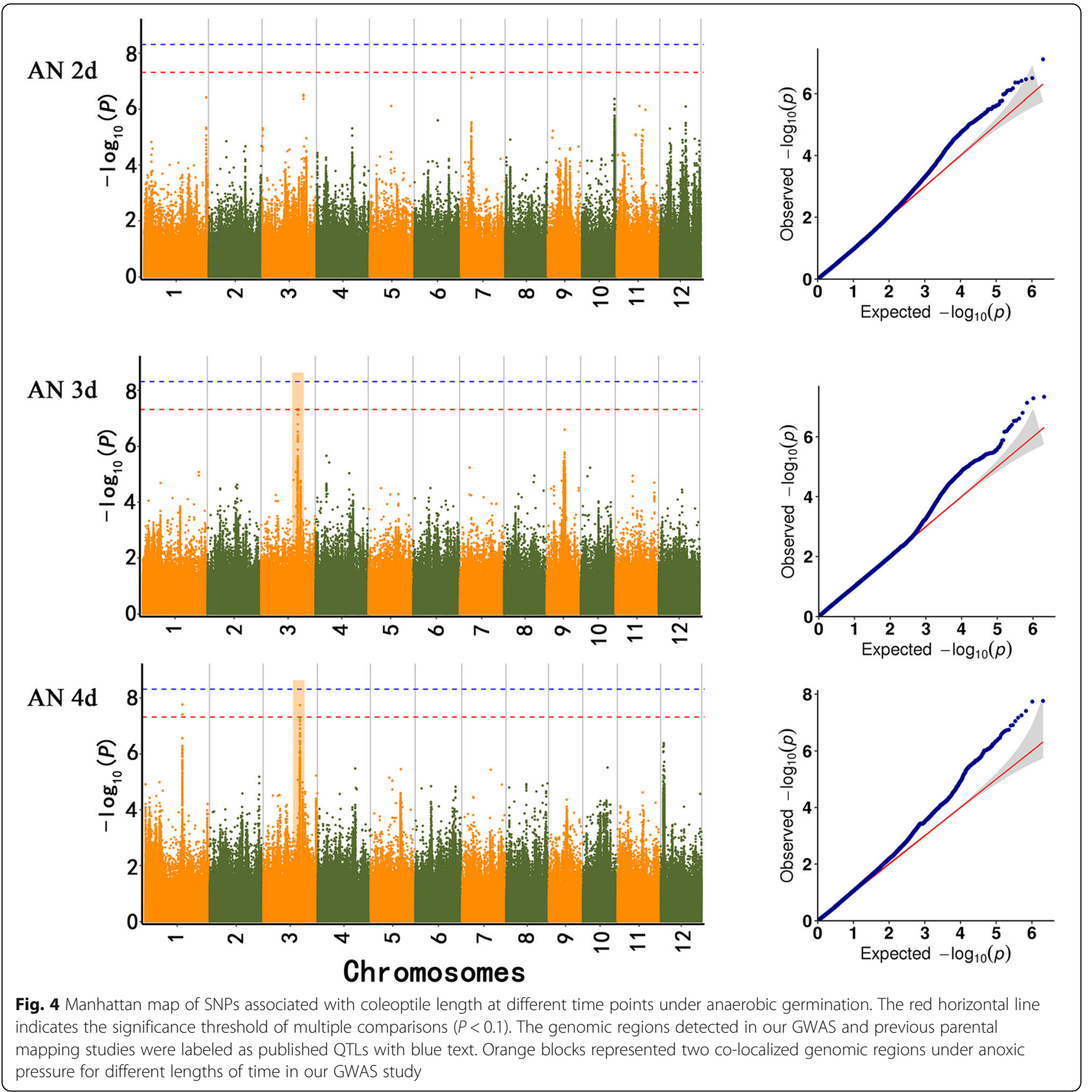

significantly associated with $C D$ was located in the genomic region of $q A G 11$, which was closely related to the submerged CL (Hsu and Tung 2015) and the anaerobic response index ( $q A G$ 11, Jiang et al. 2006; Angaji et al. 2009).

In addition, some loci were identified at multiple anoxia time points. CD was correlated with SNP S5_27918754 at AN3d and AN4d (Fig. 5), as reported in a previous study (Hsu and Tung 2015). In addition, CL was corelated with SNP S3_24689629 (Fig. 4) at AN3d and AN4d, and this result had not been reported previously.

\section{Identification of Candidate Genes}

We selected 7 loci from the GWAS results, including S3_ 24689629 and S5_27918754, which were repeatedly detected for $\mathrm{CD}$ and $\mathrm{CL}$, respectively, at both AN3d and AN4d, indicating that these two loci were highly correlated with coleoptile elongation and thickening under hypoxic conditions. In addition, S1_39674301, S6_ 20797781, S7_18722403, S8_9946213, and S11 19165397 (Hsu and Tung 2015; Yang et al. 2019a, 2019b; Septiningsih et al. 2013; Zhang et al. 2017; Jiang et al. 2006; Angaji et al. 2009) were consistent with 


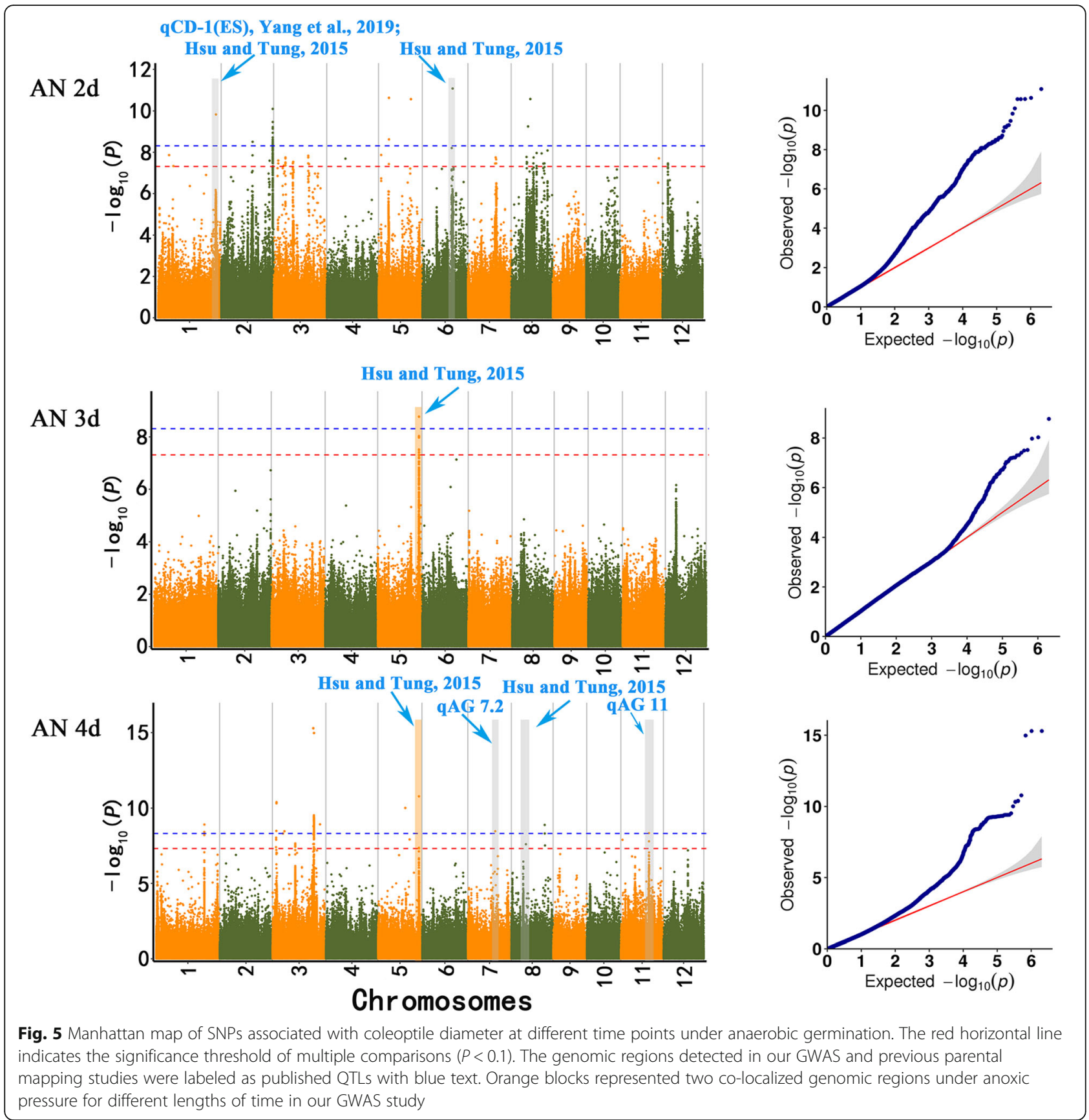

previous research results and were included. Based on the linkage disequilibrium (LD) decay distance (100$350 \mathrm{~kb}$ ) (Fig. S2), we detected a total of 106 differentially expressed genes (DEGs) in these seven trait-associated SNP sites. To more effectively identify candidate genes related to AG in rice seeds, RNA-seq analysis was carried out on RNA extracted from germinated seeds of the flooding-tolerant variety YZX at ANOd, AN2d, AN3d, AN4d, AN3dA1d, and A3dAN1d. We normalized the FPKM values of these DEGs as follows (Fig. 6): $\log _{2}$ FC (AN3dA1d/AN3d), $\log _{2}$ FC (AN3dA1d/AN4d), $\log _{2}$ FC
(A3dAN1d/A3d), and $\log _{2}$ FC (A3dAN1d/A4d). Based on the candidate gene selection criteria $\left|\log _{2} \mathrm{FC}\right| \geq 1$, FDR $\leq 0.05$ and FPKM $\geq 1$ (special: $\log 2$ FC (AN3dA1d/ AN3d), $\quad \log _{2} \quad$ FC $\quad\left(\right.$ AN3dA1d/AN4d) $\leq 1 ; \quad \log _{2} \quad$ FC (A3dAN1d/A3d), and $\log _{2}$ FC $($ A3dAN1d/A4d) $\geq 1$ ), a total of 4 DEGs were obtained.

According to the gene annotation information of the rice reference genome, we concluded that these four DEGs, gibberellin 2-beta-dioxygenase (OsGA2ox8, Os05g0560900, S5_ 27918754), berberine bridge enzyme-like 13 (Os06g0548200, S6_20797781), protein 
Table 3 Genome-wide significant associations for coleoptiles phenotype under anaerobic germination (AG) Using MLM

\begin{tabular}{|c|c|c|c|c|c|c|c|c|}
\hline Traits & SNP $^{a}$ & Chr. & Peak position $^{\text {b }}$ & $P$ value & $-\log 10(P)$ & Allleles & MAF & Known loci \\
\hline \multirow[t]{8}{*}{ CD-AN2d } & S1_ 39674301 & 1 & 39674301 & $1.48 \mathrm{E}-10$ & 9.83 & $\mathrm{~A} / \mathrm{C}$ & 0.2 & $\begin{array}{l}\text { Hsu and Tung 2015; aCD-1(ES) } \\
\text { (Yang et al. 2019a, 2019b) }\end{array}$ \\
\hline & S2_ 21568963 & 2 & 21568963 & $3.14 \mathrm{E}-09$ & 8.5 & $C / T$ & 0.2 & \\
\hline & S2_ 35360509 & 2 & 35376690 & $7.98 \mathrm{E}-11$ & 10.1 & $A / G$ & 0.2 & \\
\hline & S5_ 7135836 & 5 & 7135836 & $2.32 \mathrm{E}-11$ & 10.63 & $C / T$ & 0.1 & \\
\hline & S5_22190175 & 5 & 22190175 & $2.69 \mathrm{E}-11$ & 10.57 & $\mathrm{G} / \mathrm{A}$ & 0.2 & \\
\hline & S6_ 20797781 & 6 & 20797781 & $8.49 \mathrm{E}-12$ & 11.07 & $\mathrm{G} / \mathrm{A}$ & 0.1 & Hsu and Tung 2015 \\
\hline & S8_ 13123867 & 8 & 13123867 & 2.65E-11 & 10.58 & $\mathrm{G} / \mathrm{T}$ & 0.1 & \\
\hline & S8_ 11595732 & 8 & 11595732 & $5.64 \mathrm{E}-10$ & 9.25 & $A / T$ & 0.1 & \\
\hline CD-AN3d & S5_ 27918754 & 5 & 27918754 & 1.69E-09 & 8.77 & $\mathrm{~A} / \mathrm{G}$ & 0.4 & Hsu and Tung 2015 \\
\hline \multirow[t]{14}{*}{ CD-AN4d } & S1_ 32866906 & 1 & 32866906 & $1.24 \mathrm{E}-09$ & 8.91 & $\mathrm{G} / \mathrm{A}$ & 0.2 & \\
\hline & S3_ 27854371 & 3 & 27854371 & $5.11 \mathrm{E}-16$ & 15.29 & $A / G$ & 0.3 & \\
\hline & S3_ 2828271 & 3 & 2828271 & 4.16E-11 & 10.38 & $A / G$ & 0.2 & \\
\hline & S3_ 28290634 & 3 & 28290634 & $3.02 \mathrm{E}-10$ & 9.52 & $\mathrm{G} / \mathrm{A}$ & 0.1 & \\
\hline & S3_ 32459722 & 3 & 32459722 & 1.20E-09 & 8.92 & $C / T$ & 0.5 & \\
\hline & S3_ 7243651 & 3 & 7243651 & 4.89E-09 & 8.31 & $C / A$ & 0.2 & \\
\hline & S3_ 15571447 & 3 & 15571447 & 2.23E-08 & 7.65 & $\mathrm{G} / \mathrm{T}$ & 0.3 & \\
\hline & S5_ 27918754 & 5 & 27918754 & $1.72 \mathrm{E}-11$ & 10.76 & $A / G$ & 0.4 & Hsu and Tung 2015 \\
\hline & S5_ 18621890 & 5 & 18621890 & $9.76 \mathrm{E}-11$ & 10.01 & $\mathrm{~A} / \mathrm{C}$ & 0.1 & \\
\hline & S5_21585755 & 5 & 21585755 & $1.21 \mathrm{E}-08$ & 7.92 & T/A & 0.2 & \\
\hline & S7_ 18722403 & 7 & 18722403 & 3.45E-09 & 8.46 & T/C & 0.2 & $\begin{array}{l}\text { qAG } 7.2 \text { (Septiningsih et al. 2013; } \\
\text { Hsu and Tung 2015) }\end{array}$ \\
\hline & S8_22721012 & 8 & 22721012 & 1.31E-09 & 8.88 & $A / G$ & 0.2 & \\
\hline & S8_ 9946213 & 8 & 9946213 & $2.51 \mathrm{E}-08$ & 7.6 & T/A & 0.2 & Hsu and Tung 2015 \\
\hline & S11_ 19165397 & 11 & 19165397 & 4.62E-09 & 8.34 & $C / A$ & 0.3 & $\begin{array}{l}\text { qAG 11(Jiang et al. 2006; Angaji } \\
\text { et al. 2009; Zhang et al. 2017) }\end{array}$ \\
\hline CL-AN3d & S3_24689629 & 3 & 24689629 & 4.71E-08 & 7.33 & $\mathrm{~T} / \mathrm{C}$ & 0.4 & \\
\hline \multirow[t]{2}{*}{ CL-AN4d } & S1_ 25099585 & 1 & 25099585 & 1.73E-08 & 7.76 & G/A & 0.2 & \\
\hline & S3_ 24689629 & 3 & 24689629 & 1.83E-08 & 7.74 & T/C & 0.4 & \\
\hline
\end{tabular}

Note: MAF minor allele frequency

${ }^{\text {a }}$ The SNP positions were based on the annotation data on Reference genome IRGSP-1.0 (RAP-DB, http://rapdb.dna.affrc.go.jp/)

${ }^{b}$ Position of the SNP showing the most significant association for AG

dehydration-induced 19 (OsDi19-1, Os05g0562200, S5 27918754), and B3 domain-containing protein VP1 (OSVP1, Os01g0911700, S1_39674301), had major impacts on AG in rice seeds. The results of qRT-PCR (Fig. 7, Table S7) were similar to the results of RNA-seq. These four genes were specifically expressed under hypoxic conditions, their expression levels increased with increasing hypoxia time, and their expression levels decreased after transfer to aerobic conditions. In addition, we also referred to the transcriptome data of Lasanthi-Kudahettige et al. (2007) (Table S8), we found that the expression levels of these four genes in coleoptile of anoxia for 4 days were higher than that under aerobic conditions, which indicated that these four genes were induced by anoxia and participated in seed germination. These results indicated that these four DEGs had strong correlations with submerged germination in rice.

\section{Four New Genes Related to the Anaerobic Germination Phenotype}

To further verify the associations between the candidate genes and the germinating coleoptile phenotype under AG conditions, we performed a full-length sequencing analysis of the four candidate genes in materials with extreme phenotypes (11 high-AG materials and 11 low-AG materials) (Fig. 8).

Os01g0911700 (OsVP1) encodes the VP1 protein, which contains the $\mathrm{B} 3$ domain and is a key transcription factor in the abscisic acid (ABA) signal transduction 


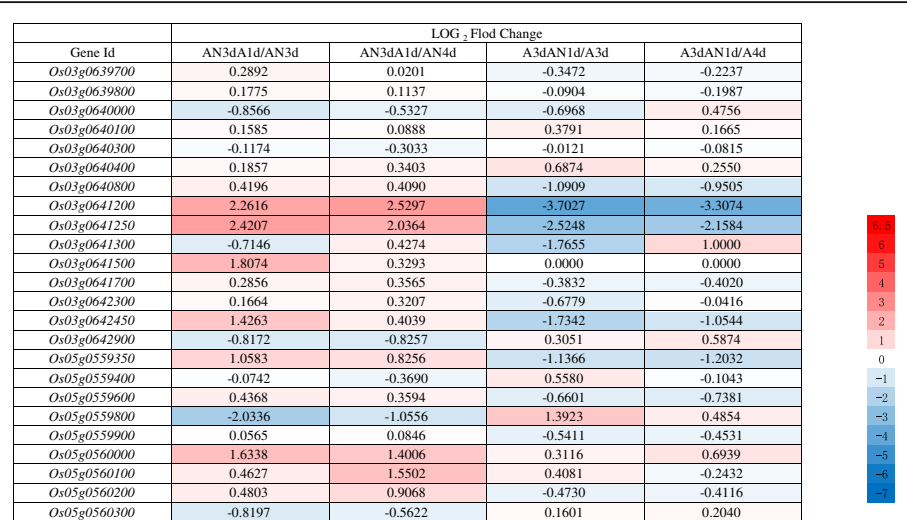

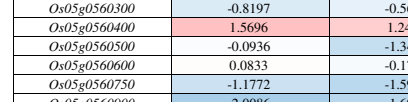

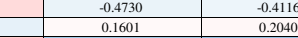

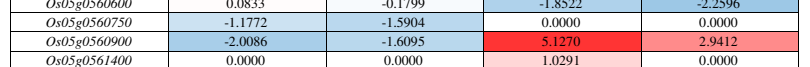

\begin{tabular}{|c|c|c|c|c|}
\hline$O s 0505661400$ & 0.0000 & 0.0000 & 1.0291 & 0.0000 \\
\hline Os05g0561500 & -0.7192 & -0.7463 & 0.8469 & 0.6161 \\
\hline
\end{tabular}

\begin{tabular}{|c|c|c|c|c|}
\hline & & & & \\
\hline Os05g0561600 & -0.9474 & -0.7196 & -0.4208 & -0.0354 \\
\hline Os05g0562000 & -1.6298 & -1.4637 & 2.8133 & 1.5210 \\
\hline Os05g0562200 & -1.2013 & -1.3680 & 2.0192 & 1.4208 \\
\hline Os 05050562300 & -0.3264 & -0.1624 & 2.1962 & 1.2252 \\
\hline
\end{tabular}

\begin{tabular}{|c|c|c|c|c|}
\hline Os $05 \mathrm{~g} 0562300$ & -0.3264 & -0.1624 & 2.1962 & 1.2252 \\
\hline Os $05 \mathrm{~g} g 562350$ & -0.3246 & 0.3263 & 1.7213 & 0.4453 \\
\hline Os05g0562400 & 0.1088 & 0.0556 & 0.0327 & -0.0406 \\
\hline Os05g0562800 & -1.2185 & -1.1693 & -1.0702 & -0.4698 \\
\hline
\end{tabular}

\begin{tabular}{|c|c|c|c|c|}
\hline & & & & \\
\hline Os05g0562800 & -1.2185 & -1.1693 & -1.0702 & -0.4698 \\
\hline Os05g0563000 & 0.8331 & 1.0841 & -3.3995 & -2.4754 \\
\hline Os05g0563050 & -0.2029 & -0.1195 & 0.5931 & 0.3344 \\
\hline Os05g0563100 & 0.3290 & 0.4615 & 1.1219 & 0.7978 \\
\hline
\end{tabular}

\begin{tabular}{|c|c|c|c|c|}
\hline & & & & \\
\hline Os05g0563100 & 0.3290 & 0.4615 & 1.1219 & 0.7978 \\
\hline Os01g0908800 & -0.8106 & -0.6277 & 0.2956 & 0.2182 \\
\hline Os01g0909000 & -0.7232 & -0.5146 & -0.8991 & -1.3451 \\
\hline Os01g0909100 & 0.9001 & 0.5581 & -0.2267 & -0.5171 \\
\hline
\end{tabular}

\begin{tabular}{|c|c|c|c|c|}
\hline Os01g0909100 & 0.9001 & 0.5581 & -0.2267 & -0.5171 \\
\hline Os $01 \lg 0909200$ & 1.0484 & 1.2094 & -1.5373 & -1.6337 \\
\hline Os01g0909300 & 3.0000 & 3.1926 & 0.0000 & 0.0000 \\
\hline Os01g0909400 & 1.2854 & 1.1010 & -2.1036 & -1.3444 \\
\hline $0 s 01 \mathrm{~g} 0909500$ & 0.2061 & 0.4460 & 0.3143 & 0.1428 \\
\hline & & 15654 & & \\
\hline
\end{tabular}

\begin{tabular}{|c|c|c|c|c|}
\hline OSOTg0909400 & & & & \\
\hline Os01g0909500 & 0.2061 & 0.4460 & 0.3143 & 0.1428 \\
\hline Os01g0910200 & 0.8197 & 1.5654 & -1.2034 & -1.3351 \\
\hline Os01g0910300 & -0.2867 & -0.3811 & 1.4001 & 0.9360 \\
\hline Os01g0910400 & 0.0000 & 1.3410 & 0.0000 & 0.0000 \\
\hline
\end{tabular}

\begin{tabular}{|c|c|c|c|c|}
\hline Os01g0910300 & -0.2867 & -0.3811 & 1.4001 & 0.9360 \\
\hline Os01g0910400 & 0.0000 & 1.3410 & 0.0000 & 0.0000 \\
\hline Os01g0910500 & 0.4063 & -0.1421 & -0.5421 & -0.2430 \\
\hline Os01g0910800 & -1.7500 & -1.7500 & -1.4463 & -2.9093 \\
\hline Os01g0910900 & -0.1709 & 0.8759 & 0.3447 & -0.6101 \\
\hline
\end{tabular}

\begin{tabular}{|c|c|c|c|c|}
\hline Os01g0910800 & -1.7500 & -1.7500 & -1.4463 & -2.9093 \\
\hline Os01g0910900 & -0.1709 & 0.8759 & 0.3447 & -0.6101 \\
\hline Os01g0911000 & 0.2999 & 0.4564 & -0.1306 & -0.2988 \\
\hline Os01g0911100 & -0.7191 & -0.6846 & 1.0572 & 0.5546 \\
\hline Os01g0911200 & 0.5735 & 0.5101 & -1.0000 & -0.9636 \\
\hline$O s 01 \mathrm{~g} 0911300$ & -0.6796 & -0.5435 & 0.3755 & 0.2199 \\
\hline
\end{tabular}

\begin{tabular}{|c|c|c|c|c|}
\hline Os01g0911100 & -0.7191 & -0.6846 & 1.0572 & 0.5546 \\
\hline & & & -1.0000 & \\
\hline Os01g0911300 & -0.6796 & -0.5435 & 0.3755 & 0.2199 \\
\hline Os01g0911700 & -0.8977 & -1.0399 & 1.4621 & 1.1708 \\
\hline
\end{tabular}

\begin{tabular}{|c|c|c|c|c|}
\hline & & & & \\
\hline Os01g0911700 & -0.8977 & -1.0399 & 1.4621 & 1.1708 \\
\hline Os01g0911800 & 0.1197 & 0.2424 & 0.0938 & -0.1536 \\
\hline Os01g0911900 & 0.6559 & 0.4947 & -0.1777 & -0.3530 \\
\hline Os06g0547400 & 0.7524 & 0.6162 & 0.6937 & 0.6964 \\
\hline Os06g0547900 & 1.3072 & 1.5868 & -1.6828 & -1.4581 \\
\hline
\end{tabular}

\begin{tabular}{|c|c|c|c|c|}
\hline Os06g0547400 & 0.7524 & 0.6162 & 0.6937 & 0.6964 \\
\hline Os $06 \mathrm{~g} 0547900$ & 1.3072 & 1.5868 & -1.6828 & -1.4581 \\
\hline Os06g0548000 & 0.4804 & 0.3770 & 1.2336 & 0.8700 \\
\hline Os06g0548100 & 1.1215 & 1.2118 & 0.5568 & 0.8152 \\
\hline Os06g0548200 & -0.7344 & -1.0782 & 3.6078 & 1.6576 \\
\hline Os06g0549300 & 2.0268 & 2.3363 & -1.7971 & -1.6619 \\
\hline
\end{tabular}

\begin{tabular}{|c|c|c|c|c|}
\hline Os06g0548200 & -0.7344 & -1.0782 & 3.6078 & 1.6576 \\
\hline Os06g0549300 & 2.0268 & 2.3363 & -1.7971 & -1.6619 \\
\hline Os06g0549600 & 0.1855 & -0.1427 & -0.6911 & -1.1654 \\
\hline$O S 06 \mathrm{~g} 0549633$ & -0.2224 & 0,0000 & 00000 & 0.0000 \\
\hline $0 \times 060549700$ & 0.1460 & 0.6477 & 04983 & 04857 \\
\hline
\end{tabular}

\begin{tabular}{|c|c|c|c|c|}
\hline Os06g0549600 & 0.1855 & -0.1427 & -0.6911 & -1.1654 \\
\hline Os06g0549633 & -0.2224 & 0.0000 & 0.0000 & 0.0000 \\
\hline Os0600549700 & 0.1460 & 0.6477 & 0.4983 & 0.4857 \\
\hline Os0600549900 & 1.3635 & 1.7217 & -0.0238 & -0.4034 \\
\hline Os06g0550000 & 1.7111 & 1.6300 & -1.6283 & -0.7527 \\
\hline
\end{tabular}

\begin{tabular}{|c|c|c|c|c|}
\hline & & & & \\
\hline Os06g0549900 & 1.3635 & 1.7217 & -0.0238 & -0.4034 \\
\hline Os06g0550000 & 1.7111 & 1.6300 & -1.6283 & -0.7527 \\
\hline Os06g0550800 & -0.3242 & -0.3649 & -0.3881 & -0.3771 \\
\hline Os06g0551000 & -0.0995 & 0.0000 & 0.0000 & 0.0000 \\
\hline Os06g0551400 & 0.0489 & -0.0886 & 0.1141 & 0.1149 \\
\hline Os07g0496900 & 0.1673 & -0.2183 & -0.3382 & -0.0898 \\
\hline
\end{tabular}

\begin{tabular}{|c|c|c|c|c|}
\hline Os07g0496900 & 0.1673 & -0.2183 & -0.3382 & -0.0898 \\
\hline$O s 07 g 0497000$ & 0.1766 & 0.0894 & -0.0507 & -0.0503 \\
\hline Os07g0497100 & 0.2405 & 0.4347 & 0.5809 & -0.2552 \\
\hline Os07g0497400 & 0.7096 & 0.8943 & -0.6047 & -0.9012 \\
\hline Os07g0497500 & -1.3904 & -1.6896 & 0.0050 & 0.0301 \\
\hline$O s 07 \mathrm{~g} 0498300$ & 1.4011 & 1.5269 & -1.2043 & -0.8528 \\
\hline Os07g0498400 & 3.7056 & 3.5986 & -3.0682 & -2.7013 \\
\hline$O s 07 \mathrm{~g} 0498800$ & 0.3802 & 0.4229 & -0.4128 & -0.6102 \\
\hline$O s 07 g 0498900$ & 0.4099 & 0.4559 & -1.0831 & -1.2216 \\
\hline Os07g0499300 & 1.1755 & 0.9053 & -2.3532 & -2.3703 \\
\hline $0 s 07 \mathrm{~g} 0499500$ & 3.6630 & 0.0000 & 0.0000 & 0.0000 \\
\hline$O s 07 g 0499800$ & -1.0114 & -0.6849 & 0.0316 & 0.1407 \\
\hline Os08g0262500 & 0.0000 & 0.0000 & -5.9240 & -4.6925 \\
\hline Osl1g 0525600 & 0.5643 & 0.6911 & -0.5307 & -0.4974 \\
\hline Os11g0525700 & 1.2506 & 1.4736 & -1.0489 & -1.3231 \\
\hline Os $11 \mathrm{~g} 0525800$ & 0.7771 & 1.4108 & -0.5061 & -0.3941 \\
\hline Osllg 0525900 & -2.3821 & -2.7747 & -0.7157 & -2.2110 \\
\hline Osllg 0526000 & -0.2630 & -0.0704 & 0.0000 & 0.0000 \\
\hline$O s 11 \mathrm{~g} 0526200$ & 1.6012 & 1.6969 & -1.4945 & -0.9011 \\
\hline Os11g0526800 & 0.3758 & 0.5525 & -0.3061 & -0.2678 \\
\hline Os11g0527000 & -0.9118 & -0.7924 & 1.1293 & 0.3392 \\
\hline Ost1g0527100 & -0.8095 & -0.0866 & 1.2928 & 1.8777 \\
\hline Os $11 \mathrm{~g} 0527150$ & 0.9386 & 1.6491 & -1.1220 & -1.5850 \\
\hline Osl1g0527300 & 0.3879 & 0.8540 & -1.5209 & -1.3279 \\
\hline Osllg0528200 & 0.6612 & 0.4700 & -1.6145 & -1.5621 \\
\hline Os11g0528300 & 1.5355 & 1.4784 & -0.6692 & -0.5394 \\
\hline Osl1g0528400 & 2.0815 & 3.4203 & -0.2575 & -0.8699 \\
\hline Osllg 0528500 & 3.2446 & 3.3320 & -2.3520 & -1.2940 \\
\hline Os11g0528700 & 3.9553 & 6.4147 & -3.8569 & -3.2869 \\
\hline Os $11 \mathrm{~g} 0529550$ & 0.0000 & 0.0000 & 0.0000 & 2.6049 \\
\hline$O s 11 \mathrm{~g} 0529900$ & 0.0000 & 0.0000 & -1.0275 & -1.0544 \\
\hline
\end{tabular}

Fig. 6 Heat map of the fold changes of the 106 candidate differentially expressed genes (DEGs) 


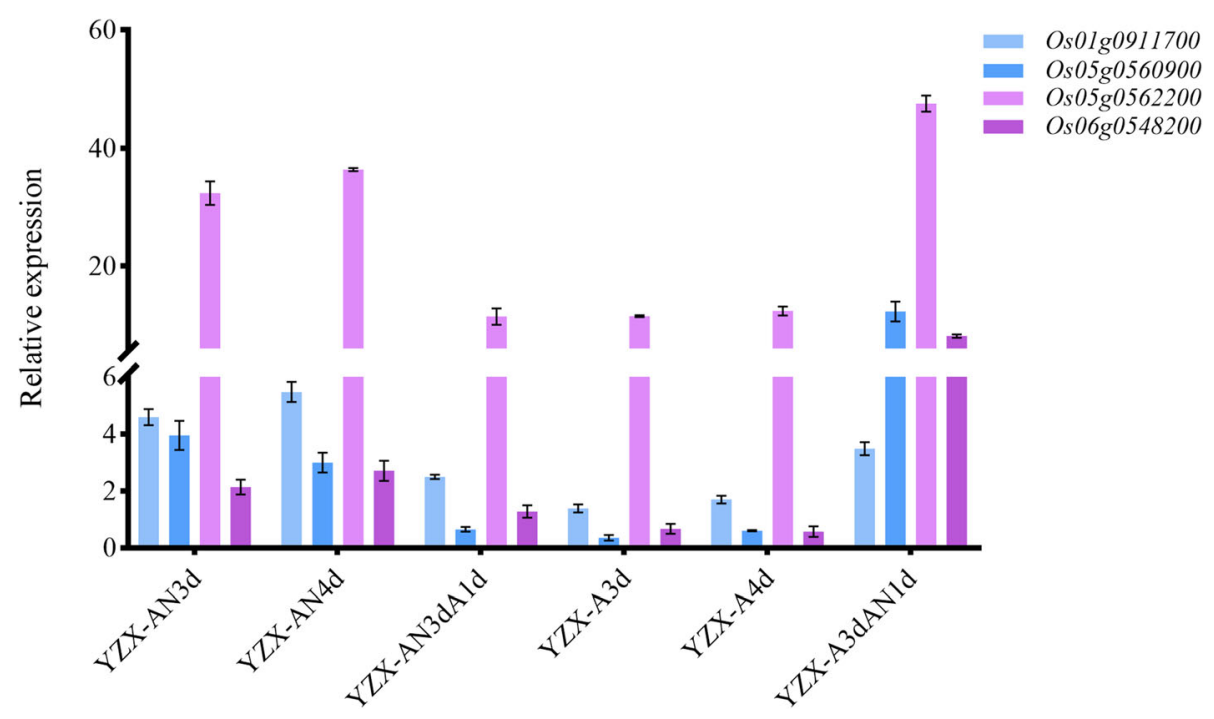

Fig. 7 qRT-PCR expression profile of four most promising candidate genes in different oxygen environments. Values are the means \pm standard errors $(n=3)$. A is for aerobic environment, AN is for anaerobic environment, AN3dA1d is for anaerobic environment and A3dAN1d is for aerobic environment and anaerobic environment

pathway. Among the 11 high-AG materials and 11 lowAG materials, we identified 11 allelic variants and 3 haplotypes of this gene (Fig. 8a). Of the 11 allelic variations, 10 included mutation sites within the gene, and these sites were mainly distributed in the first, third and sixth exon regions. The 11 high-AG varieties were different from the low-AG varieties at these 10 loci. The haplotype analysis of the extreme materials showed that Hap. 2 (compared to Hap.3, all the variable sites except +470 , downstream of the start codon, were different) was associated with the high-AG phenotype based on the traits of the coleoptile at AN4d. The average CL value was $2.932 \mathrm{~cm}$. Plants carrying Hap. 3 (in which none of the 11 variable sites were mutated) all had the low-AG phenotype, and the average CL value at AN4d was $0.257 \mathrm{~cm}$ (Table S5). we conjecture that the mutations at the remaining 10 sites have a greater impact on the AG phenotype than the mutation at site +470 (downstream of the start codon). Among them, +3143 is located in the highly conserved C-terminal B3 domain, coding for aa (D); $+470,+551,+809,+2142$ are synonymous mutations, encoding aa (D), aa (D), aa (A), aa (E); $+2017,+2622,+2734,+2771,+2997$ are non coding region variants. + 3587 is located in the 3'UTR region. It is A (reference sequence) in high-AG haplotype and $\mathrm{G}$ (mutation type) in low-AG haplotype.

The Os05g0560900 (OsGA2ox8) gene encodes a gibberellin 2-beta-dioxygenase, which is involved in GA catabolism. From the gene sequences of the 11 high-AG materials and 11 low-AG materials, we identified 17 allelic variations (Fig. 8b), which were mainly located in the first intron region. Two were located in the first and third exon regions, and the first was located at position $366(\mathrm{C} \rightarrow \mathrm{T})$ after the start codon, causing a missense mutation of glycine (G) to serine(S). The second was located at position $1420(\mathrm{~A} \rightarrow \mathrm{T})$ after the start codon, causing a missense mutation from glutamine $(\mathrm{Q})$ to leucine (L). They are both located in low complexity domains, not important functional regions of proteins encoded by OsGA2ox8, and may have less impact on the function of the proteins they encode. Haplotype analysis showed 8 haplotypes in these 22 extreme materials (Table S5). Among them, Hap.2 was associated with the high-AG phenotype. From the perspective of gene sequence, the high-AG phenotype appeared to be caused by a heterozygous mutation or deletion at +1170 (downstream of the start codon) and was apparent in seedlings at AN4d, when the average CL was $2.931 \mathrm{~cm}$. Hap. 5 and Hap.6 had missense mutations in the first exon (+366) and the third exon $(+1420)$. Because the mutations at these two sites do not fall in important functional regions of the proteins that code for OsGA2ox8, plants with these haplotypes showed both high-AG and lowAG phenotypes, and their average CL values at AN4d were $2.412 / 2.274$ and $0.296 / 0.284 \mathrm{~cm}$, respectively. In contrast, Hap. 8 was associated with the low-AG phenotype, and the average CL value of plants with this haplotype at AN4d was $0.257 \mathrm{~cm}$ (Table S5). In addition, 12 of the 17 SNPs were concentrated in the first intron region. Noncoding RNA regions can participate in gene expression regulation in various forms, including tRNA, rRNA, small nuclear RNAs (snoRNA), small nuclear RNA (snRNA), microRNA (miRNA), long noncoding RNA (lncrna), and pseudogene (Mayr 


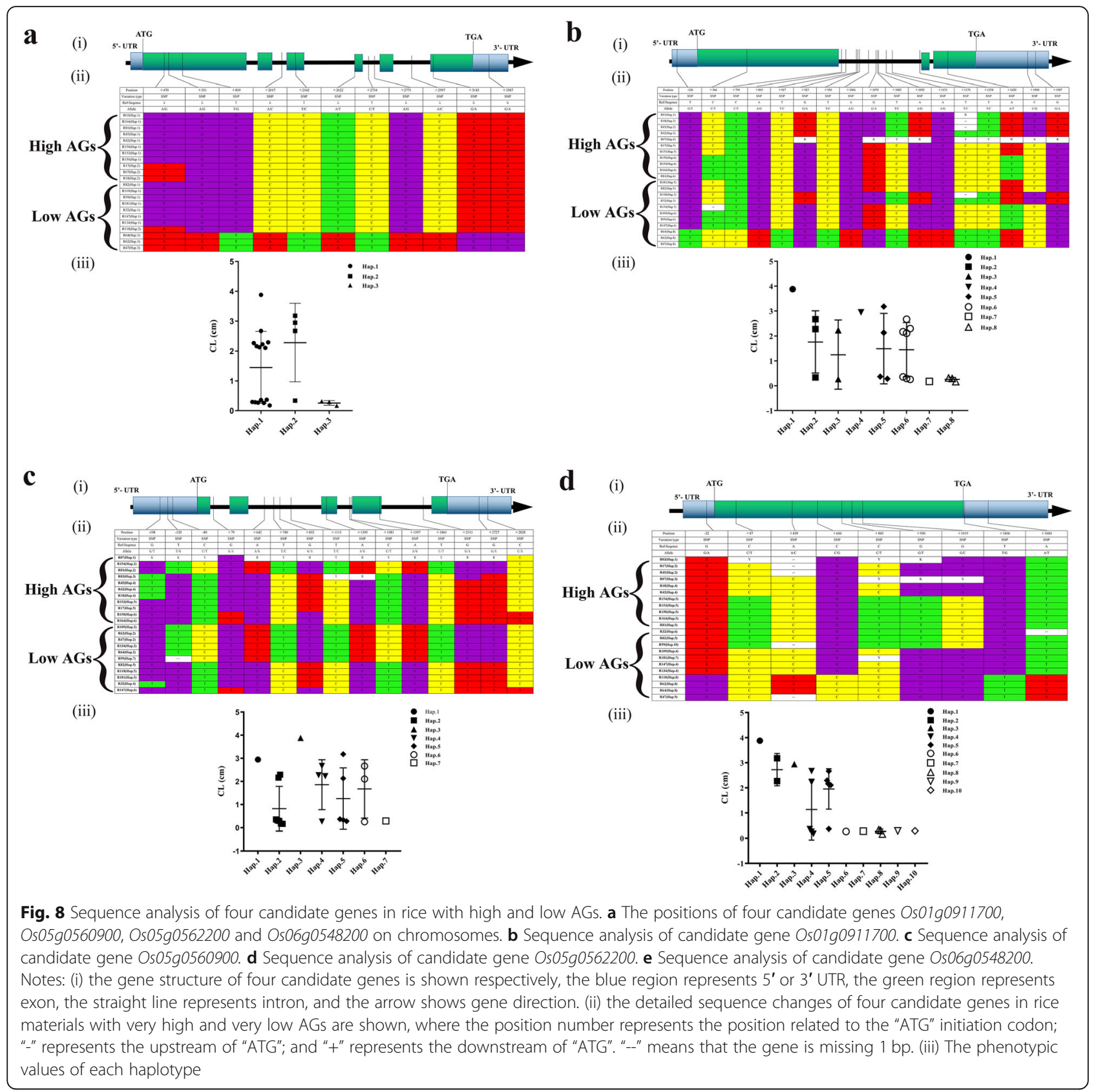

2015). Hap. 2 and Hap. 8 with extreme phenotype showed different genotypes at these 12 loci, which may imply that the mutations in these non coding regions also have potential effects on seed germination under submerging stress.

Os05g0562200 (OsDi19-1) encodes the dehydrationinduced Dil9 protein, which contains two zf-Di19 and one Di19_C domains. From the gene sequences of 22 (11 high-AG and 11 low-AG) materials, we identified 15 allelic variants, all of which were located within the gene (Fig. 8c). The gene sequences of the low-AG material were mainly similar to the sequence of the reference genome, and the gene sequences of the high-AG material harboured different mutations at these 15 loci. We speculated that these 15 allelic variations were closely related to the high-AG phenotype. In particular, $\mathrm{T} \rightarrow \mathrm{C}$ at the position of +1860 caused a missense mutation, which was located in the C-terminal domain of Di19. Its SIFT score is $0.2(<0.5)$. SIFT Score showed that this SNP had a great impact on the function of proteins. Haplotype analysis showed 7 haplotypes among these 22 extreme materials (Fig. 8c). Hap.2 was the reference genome sequence, and Hap.2 plants mainly showed the lowAG phenotype, with an average CL value at AN4d of 


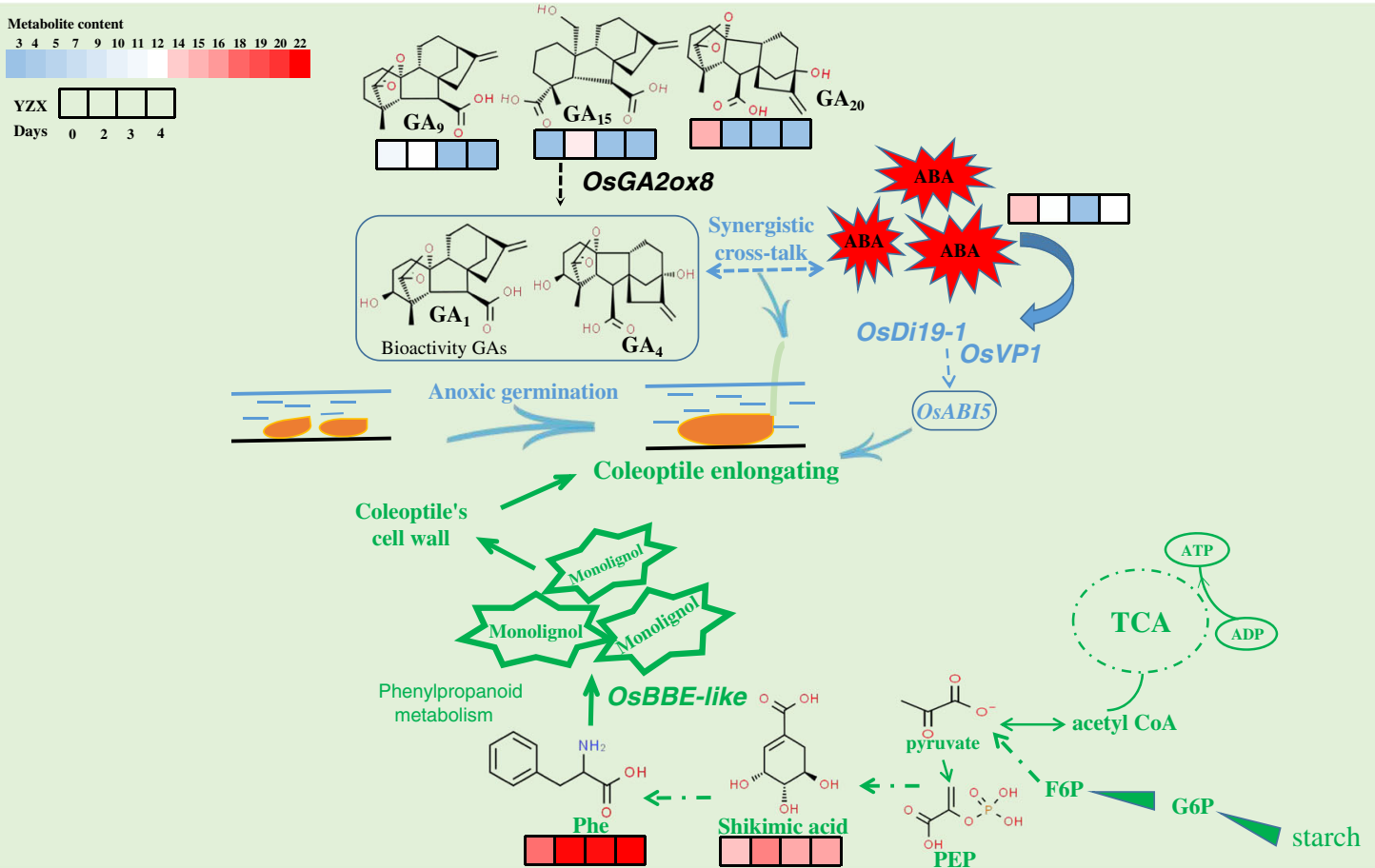

Fig. 9 Proposed mechanism of four candidate genes function in enhancing anaerobic germination. Abbreviations are as follows: G6P, Glucose-6phosphate; F6P, Fructose-6-phosphate; PEP, phosphoenolpyruvic acid; Phe, phenylalanine; TCA, tricarboxylic acid cycle

$0.288 \mathrm{~cm}$. Hap. 4 plants mainly showed the high-AG phenotype, the average $C L$ values were $2.391 \mathrm{~cm}$ (Table S5). C-terminal domain of Di19, a protein that increases the sensitivity of plants to environmental stress, such as salinity, drought, osmotic stress and cold. The protein is also induced by an increased supply of stress-related hormones such as abscisic acid ABA and ethylene (Li et al., 2010). High-AG material +1860 position is mutant base $C$, while low-AG material is $\mathrm{T}$. We hypothesized that the mutation at this site might have an effect on the germination tolerance of different rice germplasm to anaerobic germination.

Os06g0548200 encodes berberine bridge enzyme (BBE). We selected 11 high-AG and 11 low-AG materials and identified 9 allelic variations in their gene sequences (Fig. 8d) that were potentially related to the AG phenotype. One missense mutation was located 87 bases downstream of the start codon $(\mathrm{C} \rightarrow \mathrm{T}$, alanine $(\mathrm{A})$ to threonine $(\mathrm{T})$ ), which was located in FAD-binding domain. And its SIFT (Sorting Intolerant From Tolerant) score is $0.6(>0.5)$. A missense mutation was located 439 bases downstream of the start codon $(\mathrm{C} \rightarrow \mathrm{A}$, leucine (L) to arginine (R)). It was located in N-terminal of FAD linked oxidase, its SIFT score is $0.51(>0.5)$. A missense mutation was located 644 bases downstream of the start codon (C $\rightarrow$ G, glutamic (E) to aspartic (D)), it was also located in $\mathrm{N}$-terminal of FAD linked oxidase. But its
SIFT score is $1(>0.5)$, it shows that it has little effect on the function of coding protein. A missense mutation $(\mathrm{T} \rightarrow \mathrm{G})$ located 930 bases downstream of the start codon resulted in an aa substitution from arginine (R) to serine (S). It is not in the important functional region of the protein encoded by OsO6g0548200. However, its SIFT score is $0.08(<0.5)$. SIFT Score showed that this SNP was harmful and had a great impact on the function of proteins. In particular, $-32,+644,+1607$ and +1685 had only one genotype (mutant type) in the high-AG materials, while there were two different genotypes (mutant and reference genotypes) in the low-AG materials, and these had polymorphisms located in the UTR and outside the exon regions. Haplotype analysis showed 10 haplotypes in these 22 extreme materials (Table S5), of which Hap.5 showed a high-AG phenotype, and its average CL at AN4d was $2.274 \mathrm{~cm}$. Hap.8 showed a low-AG phenotype, and its average CL at AN4d was $0.273 \mathrm{~cm}$ (Table S5). Hap.5 had mutations at $-31,+645,+1607$, and +1685 , and Hap. 8 had the opposite pattern, so we believe that these four sites may be closely related to the high-AG phenotype.

\section{Metabolic Spectrum Detection of Rice Seeds under Anaerobic Germination}

LC-MS/MS was used to obtain the mass spectrum data of samples, and qualitative and quantitative analysis was carried out on the basis of a self-established database 


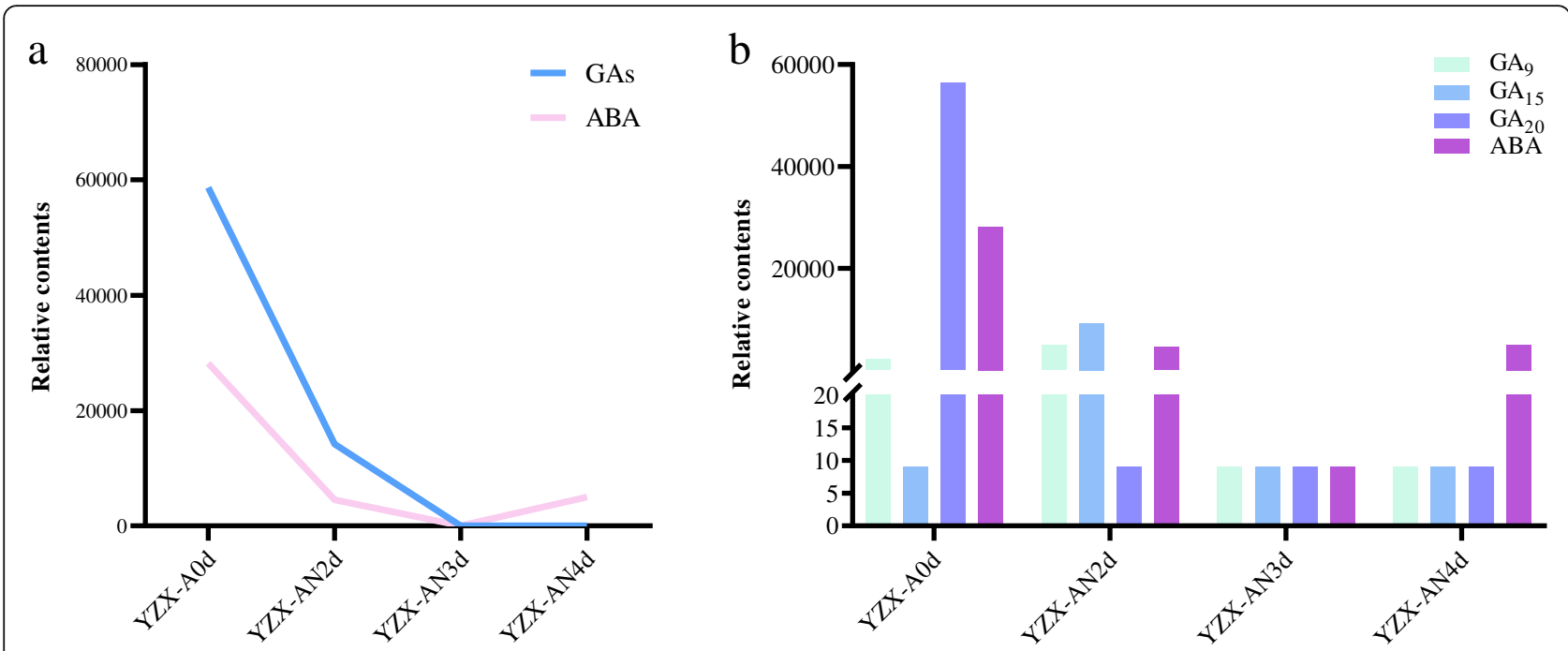

Fig. 10 a The relative content of gas and $A B A$ in $Y Z X$ seeds at different submerging time points. $\mathbf{b}$ The relative contents of three kinds of GA: $\mathrm{GA}_{9} / \mathrm{GA}_{15} / \mathrm{GA}_{20}$ and $\mathrm{ABA}$ under the condition of anaerobic germination. $\mathrm{AN}$ is for anaerobic environment

(MWDB) by Metware Company and public metabolite information database. In total, 730 metabolites were identified, including 32 substances and their derivatives (Table S3).

Through the detection of metabolites in the seeds of the YZX rice variety during AG, we found that the contents of metabolites regulated by the four genes identified above were specifically correlated with hypoxic stress. Among them, we detected three biologically active GAs, $\mathrm{GA}_{9}, \mathrm{GA}_{15}$, and $\mathrm{GA}_{20}$, which are related to the regulation of $\mathrm{GA}$ catabolism by the OsGA2ox8 (Os05g0560900) gene. The contents of $\mathrm{GA}_{9}$ and $\mathrm{GA}_{15}$ increased within 2 days after submergence, and the content at AN4d decreased compared to that at AN3d; the content of $\mathrm{GA}_{20}$ decreased to its lowest value within 2 days after submerging and then did not change (Table S3, Fig. 10). OsVP1 (Os01g0911700) and OsDi19-1 (Os05g0562200) participated in the regulation of ABArelated phenotypes. Quantitative results showed that ABA content decreased within 3 days after submerging and then suddenly increased on the fourth day (Table S3, Fig. 10). The BBE-like enzyme encoded by Os06g0548200 is involved in plant phenylpropanoid metabolism. Quantitative results showed that the contents of shikimic acid and Phe increased with increasing submerging time (Table S3, Fig. 9).

\section{Discussion}

In rice production in Asia, due to rising costs, labour shortages and water shortages, farmers often choose to plant directly in rain-fed and irrigation systems (Miro and Ismail 2013). In this case, the ability of rice to withstand flooding during germination is crucial. Rice seeds can germinate under hypoxic or even anaerobic conditions and extend the coleoptile to some extent (Biswas and Yamauchi 1997; Ella and Setter 1999), but growth during AG and the early seedling stage is extremely sensitive to anaerobic conditions (Yamauchi et al. 1993; Ismail et al. 2009; Angaji et al. 2010). Only tolerant genotypes have the ability to rapidly extend the coleoptile and form roots under submerged conditions in the field (Ismail et al. 2009). In contrast, the coleoptiles of sensitive genotypes grow more slowly, and the seedlings cannot develop further. It has been speculated that most rice genotypes can initiate germination but cannot complete it. Similar studies have reported the use of GWAS methods to mine functional genes for AG in rice, but few accessions have been used, and dynamic GWAS analysis examining the germination stage and evidence for targeted genes have been lacking (Hsu and Tung 2015; Zhang et al. 2017; Nghi et al. 2019). In this study, a high-density SNP marker set based on resequencing was used to perform a GWAS on the CL and CD of 209 diverse rice materials with RNASeq based on a differential expression profiling strategy. We identified 4 notable genes, and their expression levels were consistent with changes in the coleoptile phenotype under AG conditions. Furthermore, we used LC-MS/MS extensive targeted metabolic detection technology to verify the contents of metabolites related to the regulatory pathways associated with these four genes to support their importance in rice AG tolerance. These results may further enhance our understanding of AG in rice and help to explore the genetic mechanisms of rice AG during flooding.

The plant genome contains a large number of genes encoding $\mathrm{BBE}$, and the $\mathrm{BBE}$ protein family is widespread 
in the plant kingdom and involved in plant phenylpropanoid metabolism. Phenylpropanoid metabolism is an important pathway for the synthesis of secondary metabolites in plants. All substances containing a phenylpropane skeleton are directly or indirectly produced by this pathway. These compounds have multiple functions in plants (Schadel and Walter 1981). In recent years, in the process of genome sequencing, many genes encoding BBE-like enzymes have been identified in plants and bacteria. In the model plant Arabidopsis thaliana, 28 BBE-like genes referred to as AtBBE-like 1-28 (Wallner et al. 2013) were identified and found to be expressed in certain developmental stages of Arabidopsis, such as elongation and maturation, proliferation and embryonic development (Winter et al. 2007). Daniel et al. (2015) found that the two enzymes At-BBE-like 13 and AtBBE-like 15 may be involved in the mobilization and oxidation of the monolignols required for the polymerization process of the plant cell wall (such as lignification), while the BBE-like 15 enzyme family and potentially members of other related families work in concert with them to mobilize building blocks from their storage forms, participate in the cell wall formation required by Arabidopsis growth, and respond to stressors. Our dynamic GWAS correlation analysis found that Os06g0548200 is located in a genomic region significantly correlated with $\mathrm{CD}$ and is highly expressed in the coleoptile under hypoxic conditions. In the early stage, we found that fructose hexaphosphate (F-6-P) is an important metabolite produced in response to AG in rice seeds. F-6-P provides energy through glycolysis and participates in the production of compounds, such as phosphoenolpyruvate (PEP), through the TCA cycle. PEP then enters phenylpropanoid metabolism through the synthesis of shikimic acid and phenylalanine (Phe) (Fig. 9). The results of our qualitative and quantitative metabolite analysis of YZX seeds during AG showed that the contents of shikimic acid and Phe increased with increasing submergence time (Table S3, Fig. 10), consistent with the expression level of Os06g0548200.

The OsGA2ox8 (Os05g0560900) gene is located in a region that was significantly associated with $C D$ at both AN3d and AN4d. It encodes gibberellin 2-betadioxygenase, which controls participation in gibberellin (GA) catabolism. GAs are a class of endogenous plant hormones that regulate growth and development throughout the life cycle of higher plants (Hooley 1994), including seed germination, hypocotyls and stem elongation, leaf extension, epidermal trichome development, flowering time, floral organ development, and fruit ripening (Yamaguchi et al. 1998; Itoh et al. 1999). For the normal growth and development of plants, it is very important to produce and maintain the optimal level of bioactivity GAs (GA1, GA3, GA4 and GA7) (Lo et al.
2017; Hedden and Phillips 2000). The concentration of GA is regulated through both synthesis and inactivation. The main GA inactivation pathway is through GA 2oxidation, which regulates GA concentration (Rieu et al. 2008). The main catabolic pathway of GA is $2 \beta$ - hydroxylation catalyzed by GA2ox. The common $\mathrm{C}_{19^{-}}$ GA2oxs class can reduce the level of bioactive GA. It can reduce the $\mathrm{C}-2$ hydroxyl of active $\mathrm{C}_{19}$-GA precursors $\left(\mathrm{GA}_{9}\right.$ and $\left.\mathrm{GA}_{20}\right)$ and $\mathrm{C}_{20}$-GA precursors $\left(\mathrm{GA}_{12}\right.$, $\mathrm{GA}_{53}$ ) (Lo et al. 2008; Sakamoto et al. 2003; Yamaguchi 2008), synthesis of bioactive $G_{1}, G A_{3}, G A_{4}$ and $G_{7}$. In Arabidopsis, ga2ox7 and ga2ox8 mutants had higher germination rates and longer coleoptiles under the action of GA biosynthetic inhibitor Pyrimidinol (Schomburg et al. 2003). Lo et al. (2008) found that moderate down-regulation of GA2ox5 and GA2ox9 in DAI 2 was associated with rapid seed germination. We found that GA2ox8 expression was up-regulated and $\mathrm{GA}_{9}, \mathrm{GA}_{15}$ and $\mathrm{GA}_{20}$ contents were decreased under hypoxia stress in rice seeds, indicating that $\mathrm{C}_{20}$-GA2ox may play a coordinating role in regulating GA content required for rice seed anoxic germination. However, it is not clear how GA2ox is differentially regulated during seed anoxic germination. We speculate that OsGA2ox8 gene may be involved in GA catabolism and inactivate the direct precursors of three kinds of bioactive GA, so as to regulate the endogenous level of bioactive GAs (such as $\mathrm{GA}_{1}$, $\mathrm{GA}_{4}$ ) and the coleoptile elongation of rice seeds. Due to the complex feedback regulatory network and the spatiotemporal expression of GA2oxs and other enzymes involved in GA biosynthesis and catabolism, as well as the interaction between GA metabolism and reaction pathways (Olszewski et al. 2002; Yamauchi et al. 2007), so we are now trying to explain the regulation mechanism of GA2ox8 expression through broader biochemical and genetic interference studies to better understand its exact function in rice hypoxia germination.

The plant hormone ABA plays central roles in seed maturation, germination and adaptation to abiotic environmental stress (Leung and Giraudat 1998). In rice, OsVP1(Os01g0911700) is a direct homologous gene in maize $A B I 3$, encoding a $\mathrm{B} 3$ domain-containing transcription factor necessary for seed response to ABA (Hattori et al. 1994; Hobo et al. 1999). OsABI5 is a homolog of ABI5 in Arabidopsis thaliana (Nijhawan et al. 2008), Zou et al. (2007) found that two alternative splicing mutants of the bZIP type transcription factor OsABI5, $O s A B I 5-1$ and $O s A B I 5-2$, may have overlapping and different functions in the regulation of downstream target genes, and regulate ABA signal as a transcription factor to express with OsVP1. In our dynamic GWAS analysis, Os01g0911700 was found in an area significantly correlated with $\mathrm{CD}$ at AN2d. The expression was upregulated in hypoxia and down regulated in aerobic 
environment (Fig. 7). ABA content fluctuated at a low level all the time, suggesting the hypoxic stress caused by flooding conditions, which caused OsVP1 to fine tune the ABA signaling pathway (Fig. 9) and promoted seed germination. In addition, Mohanty et al. (2012) through the enrichment analysis of cis elements of up-regulated and down-regulated genes responding to hypoxia, it was found that specific ABA responsive cis elements, MYBbox and ethylene responsive cis element were highly enriched in the up-regulated genes. They interacted with specific transcription factors bZIP, MYB and ERF, resulting in hypoxia regulation and acting as the main regulator of rice germination under hypoxia conditions, common to adjust coleoptile elongation. It is well known that $\mathrm{ABA}$ involved in regulation of seed dormancy and germination inhibition, this seemingly contradictory and our study, but the low oxygen adversity caused by abiotic stress on seed germination in the process of different hormone regulation may exist between collaborative crosstalk effect, this may be related to hormonal regulation in the process of normal germination differences, this is very interesting and worth our further research.

OsDi19-1 (Os05g0562200) encodes the dehydrationinduced Di19 protein, a member of a small family of plant transcription factors, and is reported to be involved in abiotic stress (Liu et al. 2013; Wang et al. 2016). OsDi19-4, a member of the rice Di19 protein family, has been reported to act as a transcription factor. Through the OsCDPK14 - OsDi19-4 - OsASPG1/ OsNAC18 regulatory pathways, it not only indirectly regulates a large number of plant stress and $\mathrm{ABA}$ response genes but also, by interacting with their promoters, directly regulates certain ABA-responsive genes (such as OsASPG1 and OsNAC18), which further modulate ABA-related phenotypes (Wang et al. 2016). In our dynamic GWAS analysis, OsDi19-1 was detected at both AN3d and AN4d, and its expression level increased with time under anaerobic conditions and when plants were transferred to anaerobic from aerobic conditions. Under aerobic conditions, its expression level decreased; thus, it specifically responded to a hypoxic environment. We quantitatively analysed ABA in YZX seeds at different time points under anaerobic germination conditions and found that the content of ABA gradually decreased in the first 3 days after flooding but suddenly increased on the 4th day. Under timed oxygen-deficiency conditions, OsDi19-1 directly or indirectly regulates ABA-related response genes, tweaking ABA content, which in turn regulates the coleoptile phenotype (Table S3, Fig. 9).

Three of the 4 candidate genes identified by our dynamic GWAS association analysis results $(\mathrm{Os} 05$ g0560900, Os01g0911700, Os05g0562200) were related to the plant hormones $\mathrm{ABA}$ and GA, which indicated that
ABA and GA play important roles in coleoptile elongation during AG in rice seeds. During the anoxic germination of rice seeds, the main energy supply was glycolysis and fermentation metabolism. During this period, cross-talk between different hormone-mediated pathways may occur to maintain ATP level and regulate sugar consumption (Mohanty et al. 2012). Quantitative analysis of GA and ABA in submerged YZX seeds showed that GA content decreased to a plateau over time, and ABA content decreased first and then increased (Table S3, Fig. 10). After 0-3 days of submergence, the GA content was 2-3 times that of $\mathrm{ABA}$; after 4 days of flooding, the GA content reached a minimum, and the ABA content increased to 185 times that of GA. These results indicate that although $\mathrm{GA}$ and $\mathrm{ABA}$ both play roles in coleoptile elongation under submerged conditions, their regulatory responses have temporal and spatial differences. How these three candidate genes participate in regulating the GA and ABA signalling regulatory pathways will be further explored in future work.

\section{Conclusion}

In this study, high-density SNP markers based on resequencing were used to perform dynamic GWAS on the coleoptile phenotypes of 209 natural rice populations, and four reliable candidate genes were identified. These genes were involved in GA and ABA signalling and cell wall metabolic processes, showed differential expression under AG conditions, and promoted coleoptile elongation, allowing seedlings to escape immersion by extending the coleoptile out of the anaerobic environment to obtain oxygen and support rapid germination.

\section{Materials and Methods \\ Plant Material and Growth Conditions}

The mapping population consisted of 209 rice accessions (Yang et al. 2019a, 2019b). The majority came from Southern China, whereas others were from Japan, the Philippines, Vietnam, Indonesia, Pakistan, India, the United States and other countries (Table S1). Seeds of the population were planted in a paddy field at South China Agricultural University, Guangzhou $\left(23^{\circ} 16^{\prime} \mathrm{N}\right.$, $113^{\circ} 8^{\prime} \mathrm{E}$ ), during the late cropping season (July-November) in 2018. The spaces between rows and between plants were 20 and $20 \mathrm{~cm}$, respectively. Thirty-six plants of each accession were grown in 6 rows with 6 plants per row. Considering that seed maturity affects anaerobic germination (AG), six individual plants in the middle of each block were harvested independently on the 40th day after heading in the late cropping season. Crop management and disease and insect pest control were performed as locally recommended. The harvested seeds 
were dried in a heated air dryer at $42^{\circ} \mathrm{C}$ for 5 days and then stored at $-20^{\circ} \mathrm{C}$ (Yang et al. 2019a, 2019b).

\section{Phenotyping}

From the six independently harvested plants, 30 healthy, fully mature seeds were selected for each accession. The seeds of each experimental cultivar were placed in an oven at $50^{\circ} \mathrm{C}$ for 5 days to break dormancy, surfacesterilized with $0.2 \% \mathrm{HgCl}_{2}$ for $5 \mathrm{~min}$ and then washed thrice with sterile distilled water. Five seeds were placed in one sterile centrifuge tube $(50 \mathrm{~mL})$, which was filled with distilled water to create anaerobic conditions. Germination took place at $30^{\circ} \mathrm{C}$ in a growth chamber in the dark. After 2, 3, and 4 days, a WinRHIZO (Regent Instruments Inc., Québec, Canada) root image analysis system was used to measure the coleoptile length (CL), coleoptile surface area (CSA), coleoptile volume (CV), and coleoptile diameter (CD). Three independent, replicated experiments were performed for each rice accession. All treatments were performed in parallel. Statistical analysis was performed with SPSS (Statistical Analysis System, version 23.0) and Microsoft Excel.

\section{Whole-Genome Resequencing and Variation Detection}

The genomes of all 209 accessions were sequenced on the Illumina HiSeq 2500 Sequencing Systems Platform (Illumina Inc. USA), with an average coverage of approximately $12 \times$. Raw reads were processed to obtain an average quality score (QS) per read $\leq 30$ by trimming the 3 ' ends of the reads using SICKLE (https://github.com/ najoshi/sickle). High-quality reads were aligned against the rice reference genome (IRGSP 1.0) (Kawahara et al. 2013) for genotype calling using Burrows - Wheeler Aligner (BWA) (version 0.7.5a).

Single nucleotide polymorphisms (SNPs) were mainly detected by the GATK (McKenna et al. 2010) software kit. According to the positioning results of clean reads in the reference genome, Picard (http://sourceforge.net/ projects/picard/) was used to filter the redundant reads (mark duplicates) to ensure the accuracy of the detection results. Finally, low-quality markers, deletion markers < $25 \%$ and minor allele frequency (MAF) $>5 \%$ were filtered, and the final set of mutation loci was obtained.

\section{Population Structure Analysis and Genome-Wide Association Mapping}

Principal component analysis (PCA), construction of a neighbour-joining (NJ) tree, determination of linkage disequilibrium (LD) decay level and kinship analysis among the landraces were performed based on SNPs. The population structure of the 209 varieties was estimated with PCA by using the software EIGENSTRAT (Tamura et al. 2007). PHYLIP version 3.695 software (http://evolution.genetics.washington.edu/phylip/getme-new1.html) was used to construct the NJ tree on the basis of similarity measures, and MEGA V6.0 was used to observe the NJ tree (Purcell et al. 2007). A Q matrix was obtained from the membership probability of each variety using ADMIXTURE version 1.22 software (Hardy and Vekemans 2002). The Q matrix was used for further association mapping. The Loiselle algorithm was chosen to construct a kinship matrix (K) with the software SPAGeDi (Kang et al. 2010). Moreover, all negative kinship values were set to zero.

Based on the developed high-density SNP molecular marker data, this study used TASSEL 4.0 (Bradbury et al. 2007), FaST-LMM (Lippert et al. 2011), and EMMAX (Yang et al. 2014) for correlation analysis. Association analysis was implemented under a mixed linear model (MLM), which could be described as $\mathrm{y}=X \alpha+$ $S \beta+K \mu+$ e. $X$ and y represented the genotype and phenotype, $\alpha$ represented the SNP effects, $\beta$ represented the effects of population structure, $\mu$ was the vector of kinship background effects, e corresponded to residual effects, $S$ was the PCA matrix relating y to $\beta$, and $K$ represented the related kinship matrix (Wen et al. 2014; Zhang et al. 2017; Yang et al. 2019a, 2019b).

The whole set of 2,123,725 SNPs was used in association mapping with a MAF criterion of $5 \%$. A genomewide threshold of $-\log (P)=7.3271$ was calculated from the formula "-log10(0.1/effective number of SNPs)" (Wu et al. 2015).

\section{LD Structure and Haplotype Analysis}

Using the software plink2 (Purcell et al. 2007), on the same chromosome, the LD between pairs of SNPs within a certain distance range $(1000 \mathrm{~kb})$ was calculated. When the LD value of the two markers dropped to half of the maximum value $\left(R^{2}=0.3\right)$, the interval was considered a candidate region where potential causal variants might reside. Gramene Mart (http://www.gramene.org/) was used to search for candidate genes in the target region (Hsu and Tung 2015).

Haplotyping of the identified candidate genes was carried out using DnaSP v5 (Librado and Rozas 2009). Candidate gene sequence analysis was based on the rice reference genome (IRGSP 1.0) to capture the nucleotide variation in the whole region of each target gene.

\section{RNA-Seq and Data Analysis of Gene Expression Profiles}

An anoxia-tolerant indica rice variety (YZX) was selected from 209 natural populations and cultured for 4 days at $30{ }^{\circ} \mathrm{C}$ under low oxygen conditions (5 seeds with hulls were put into a $50 \mathrm{ml}$ sterile centrifuge tube filled with sterile water); at the same time, a conversion treatment was carried out (after 3 days of cultivation under anaerobic conditions, they were transferred to normoxic conditions for 1 day). Each treatment was repeated 3 times, and 3-g samples of each replicate were collected every 
day, wrapped in foil, and frozen in liquid nitrogen at $80^{\circ} \mathrm{C}$ for storage. For total RNA extraction, each sample was homogenized in liquid nitrogen with a mortar and pestle, and then, the RNA was purified in accordance with the manufacturer's instructions using the Plant Total RNA Purification Kit (Comwin Biotechnology Company).

After the total RNA was extracted from the sample (seeds + coleoptiles), the mRNA was enriched with magnetic beads with oligo (DT), and fragmentation buffer was added to the mRNA to produce short fragments. Then, first-strand cDNA was synthesized with six-base random primers, and the second strand was synthesized with buffer, dNTPs, RNase $\mathrm{H}$ and DNA polymerase I. After purification with the QIAquick PCR kit and elution with EB buffer, the ends were repaired, A bases were added, and then, the target fragments were recovered by agarose gel electrophoresis. PCR amplification was used to complete the preparation of the whole cDNA library. The cDNA library was sequenced on an Illumina sequencing platform (Illumina $\mathrm{HiSeq}^{\mathrm{mi}} 2500$ ) by Gene Denovo Co. (Guangzhou, China). The reads obtained from the sequencing machines included raw reads containing adapters or low-quality bases, which would have affected the subsequent assembly and analysis. Thus, to obtain high-quality clean reads, the reads were further filtered according to the following rules: 1) removing reads containing adapters; 2) removing reads containing more than $10 \%$ unknown nucleotides $(\mathrm{N})$; and 3) removing low-quality reads containing more than $50 \%$ low-quality (Q-value $\leq 20)$ bases. All the reads that passed the filter specifications were mapped to the reference genome IRGSP-1.0, all transcripts were obtained, and their abundance was estimated by genome-guided transcription assembly using the Cufflinks package (Trapnell et al. 2012).

Differential analysis of each transcript and gene was performed using edger (Robinson et al. 2010). The error detection rate (FDR) was used to determine the threshold value of the $P$-value for multiple experiments. FDR $\leq$ 0.05 and absolute value of $\log _{2} \mathrm{FC} \geq 1$ were used to determine the significance of gene expression differences.

\section{Validation of Gene Expression by qRT-PCR}

For qRT-PCR, total RNA was extracted from rice coleoptiles after 2, 3, and 4days of germination using a MiniBEST Plant RNA Extraction kit (Takara Bio, Inc., Japan). According to the method of Guo et al. (2019), the candidate genes were analysed by qRT-PCR, and NCBI Primer BLAST (http://www.ncbi.nlm.nih.gov/ tools/primer-blast/) was used to design gene-specific primers. The primer sequences of the 4 candidate genes are shown in Table S5.

\section{Detection of Metabolites in Seeds under Anaerobic} Conditions by LC-MS/MS

To understand the metabolic process of rice seed germination under anaerobic conditions, YZX was selected for metabolite detection among the 209 accessions, and LC-MS/MS was used to detect metabolites. The test seeds were placed in an oven at $50^{\circ} \mathrm{C}$ for 5 days to break dormancy, surface sterilized with $0.2 \% \mathrm{HgCl}_{2}$ for $5 \mathrm{~min}$ and washed with sterile distilled water 3 times. Groups of 5 seeds were placed in sterile centrifuge tubes $(50 \mathrm{ml})$, which were filled with distilled water to achieve anaerobic conditions and germinated in a constanttemperature incubator at $30^{\circ} \mathrm{C}$ in darkness. After 2,3 and 4 days of AG, three biological repeats were taken from each treatment, and dry seeds were used as a control. The methods of Chen et al. (2013) were used for sample preparation, extraction and qualitative and quantitative determination of metabolites. The metabolite database used included the MWDB database established by Metware company, the metabolite information public database (MassBank (http://www.massbank.jp), KNApSAcK (http://kanaya.naist.jp/KNApSAcK), Human Metabolome Database (HMDB; http://www.hmdb.ca), MoTo DB (http://www.ab.wur.nl/moto), and METLIN (http://metlin.scripps.edu/index.php)).

\section{Supplementary Information}

The online version contains supplementary material available at https://doi. org/10.1186/s12284-020-00444-x.

Additional file 1: Fig. S1. Variation detection and annotation of SNP. a, Mutation detection of SNP in 209 rice accessions. b,SNP annotation of 209 rice accessions

Additional file 2: Fig. S2. The linkage disequilibrium (LD) decay of marker- pairs over all chromosomes for the population

Additional file 3: Table S1. Source of 209 rice accessions materials. SD means standard deviation;SE stands for standard error; CV is the coefficient of variation. Sheet 1 is the coleoptile phenotype data after 2 days of submersion; Sheet 2 is the coleoptile phenotype data after 3 days of submersion; Sheet 3 is the coleoptile phenotype data after 4 days of submersion

Additional file 4: Table S2. Phenotype of 209 rice accessions during germination under submerging

Additional file 5: Table S3. Detected metabolites. Note: Mix 1-10 are quality control (QC) samples

Additional file 6: Table S4. Contents of seven related metabolites regulated by candidate genes

Additional file 7: Table S5. Haplotype and phenotype association analysis of candidate genes in High AGs and Low AGs. Note: unit, cm Additional file 8: Table S6. qRT-PCR primer sequences of four candidate genes

Additional file 9: Table S7. qRT-PCR expression profile of four most promising candidate genes in different oxygen environments

Additional file 10: Table S8. Expression levels of 106 candidate genes in Nipponbare under anoxia and aerobic treatments (transcriptome data from Lasanthi-Kudahettige et al. (2007))

Additional file 11: Table S9. The significant SNPs for coleoptiles length $(C L)$ and diameter (CD) under anaerobic germination (AG) using 
genome-wide association. Note: a The SNP positions were based on the annotation data on Os-Nipponbare-Reference-IRGSP-1.0 (RAP-DB, http:// rapdb.dna.affrc.go.jp/; $b$ Position of the SNP showing the most significant association for $A G$

Additional file 12: Fig. S3. MRM multimodal map for metabolite detection. The panel $\mathrm{a}$ is the detection in the positive ion mode; the panel $\mathrm{b}$ is the detection in negative ion mode

\section{Abbreviations}

AG: Anaerobic germination; CL: Coleoptile length; CSA: Coleoptile surface area; CD: Coleoptile diameter; CV: Coleoptile volume; DSR: Direct-seeded rice; GWAS: Genome-wide sequencing analysis; LC-MS/MS: Liquid chromatography tandem mass spectrometry

\section{Acknowledgments}

We wish to thank all the students who participated in this project helping with the seed germination experiment. We thank Guangzhou Genedenovo and Metware Biotechnology Co., Ltd., for assisting in sequencing and bioinformatics analyses. We also thank American Journal Experts (AJE) for its linguistic assistance during the preparation of this manuscript.

\section{Authors' Contributions}

TG, ZC, HW and LS designed the project and LS performed all the experiments and wrote the manuscript. JY, DL, ZP, AX, MY, LL, CH and JW assisted in conducting the experiments and analyzing the data. HW and $\mathrm{ZC}$ provided the direction for the study and the corrections of the manuscript. All authors read and approved the final manuscript.

\section{Funding}

Financial support for this research was provided in part by a grant from the Research and Development Plan for Key Areas in Guangdong province (No. 2018B020206002), the National Key Research and Development Project (No. 2017YFD0100104), and the earmarked fund for China Agriculture Research System (No. CARS-01-17). The funder had no role in the experimental design, data collection and analysis or preparation of the manuscript.

\section{Availability of Data and Materials}

All the RNA-seq data generated in this research was deposited in the Sequence Read Archive database (www.ncbi.nlm.nih.gov/sra) at NCBI (National Center for Biotechnology Information) under accession number: SRP282222. The data sets supporting the results of this study are included in the manuscript. Rice seeds are available from the National Engineering Research Center of Plant Space Breeding, PR China.

\section{Ethics Approval and Consent to Participate}

Not applicable.

\section{Consent for Publication}

Not applicable.

\section{Competing Interests}

The authors declare that they have no competing interests.

\section{Received: 5 June 2020 Accepted: 6 December 2020}

Published online: 06 January 2021

\section{References}

Alexander DH, Novembre J, Lange K (2009) Fast model-based estimation of ancestry in unrelated individuals. Genome Res 19:1655-1664

Alpi A, Beevers $\mathrm{H}$ (1983) Effects of $\mathrm{O}_{2}$ concentration on rice seedlings. Plant Physiol 71(1):30-34

Angaji SA (2008) Mapping QTLs for submergence tolerance during germination in rice. Afr J Biotechnol 7:2551-2558. https://doi.org/10. 1007/s00122-013-2057-1

Angaji SA, Septiningsih EM, Mackill DJ, Ismail AM (2009) QTLs associated with tolerance of flooding during germination in rice (Oryza sativa L.). Euphytica 172:159-168. https://doi.org/10.1007/s10681-009-0014-5

Angaji SA, Septiningsih EM, Mackill DJ, Ismail AM (2010) QTLs associated with tolerance of flooding during germination in rice (Oryza sativa L.). Euphytica. 172:159-168
Baltazar MD, Ignacio JCl, Thomson MJ, Ismail AM, Mendioro MS, Septiningsih EM (2014) QTL mapping for tolerance of anaerobic germination from IR64 and the aus landrace Nanhi using SNP genotyping. Euphytica 197(2):251-260

Biswas JK, Yamauchi M (1997) Mechanism of seedling establishment of direct-seeded rice (Oryza sativa L.) under low land conditions. Bot Bull Acad Sin 38:29-32

Bradbury PJ, Zhang Z, Kroon DE, Casstevens TM, Ramdoss Y, Buckler ES (2007) TASSEL: software for association mapping of complex traits in diverse samples. Bioinformatics 23:2633-2635. https://doi.org/10.1093/ bioinformatics/btm308

Chen W, Gong L, Guo Z, Wang W, Zhang H, Liu X, Yu S, Xiong L, Luo J (2013) A novel integrated method for large-scale detection, identification, and quantification of widely targeted metabolites: application in the study of Rice metabolomics. Mol Plant 6:1769-1780

Chen HD, Xie WB, He H, Yu HH, Chen W, Li J, Yu R, Yao Y, Zhang WH, He YQ Tang XY, Zhou FS, Deng XW, Zhang QF (2014) A high-density SNP genotyping array for rice biology and molecular breeding. Mol Plant 7:541553. https://doi.org/10.1093/mp/sst135

Cho Jl, Ryoo N, Eom JS, Lee DW, Kim HB, Jeong SW, Lee YH, Kwon YK, Cho MH, Bhoo SH, Hahn TR, Park YI, Hwang I, Sheen J, Jeon JS (2009) Role of the Rice hexokinases OsHXK5 and OsHXK6 as glucose sensors. Plant Physiol 149:745759. https://doi.org/10.1104/pp.108.131227

Daniel B, Pavkov-Keller T, Steiner B, Dordic A, Gutmann A, Nidetzky B, Sensen CW, van der Graaff E, Wallner S, Gruber K, Macheroux P (2015) Oxidation of monolignols by members of the berberine bridge enzyme family suggests a role in plant cell wall metabolism. J Biol Chem 290:18770-18781

Ella ES, Setter TL (1999) Importance of seed carbohydrates in rice seedling establishment under anoxia. Acta Hortic 504:209-216

Fred TT, Chen CC, Garry NM (1981) Morphological development of rice seedling in water at controlled oxygen levels. Agron J 73:556-560

Granot D, David-Schwartz R, Kelly G (2013) Hexose kinases and their role in sugar-sensing and plant development. Front Plant Sci https://doi.org/10. 3389/fpls.2013.00044

Granot D, Kelly G, Stein O, David-Schwartz R (2014) Substantial roles of hexokinase and Fructokinase in the effects of sugars on plant physiology and development. J Exp Bot 65:809-819. https://doi.org/10.1093/jxb/ert400

Guo T, Yang J, Li DX, Sun K, Luo LX, Xiao WM, Wang JF, Liu YZ, Wang S, Wang H, Chen ZQ (2019) Integrating GWAS, QTL, mapping and RNA-seq to identify candidate genes for seed vigor in rice (Oryza sativa L.). Mol Breeding 39:87. https://doi.org/10.1007/s11032-019-0993-4

Hardy OJ, Vekemans X (2002) SPAGeDi: a versatile computer program to analyse spatial genetic structure at the individual or population levels. Mol Ecol Notes 2:618-620

Hattori T, Terada T, Hamasuna S (1994) Sequence and functional analyses of the rice gene homologous to the maize VP1. Plant Mol Biol 24(5):805-810

Hedden P, Phillips AL (2000) Gibberellin metabolism: new insights revealed by the genes. Trends Plant Sci 5(12):523-530

Hobo T, Kowyama Y, Hattori T (1999) A bZIP factor, TRAB1, interacts with VP1 and mediates abscisic acid-induced transcription. Proc Natl Acad Sci U S A 96(26): 15348-15353

Hooley R (1994) Gibberellins: perception, Transduction and Responses. Plant Mol Biol 26:1529-1555

Hsu SK, Tung CW (2015) Genetic mapping of anaerobic germination associated QTLs controlling coleoptile elongation in rice. Rice 8:38. https://doi.org/10. 1186/s12284-015-0072-3

Huang S, Taylor NL, Narsai R, Eubel H, Whelan J, Millar AH (2009) Experimental analysis of the Rice mitochondrial proteome, its biogenesis, and heterogeneity. Plant Physiol 149:719-734. https:/doi.org/10.1104/pp.108.131300

Huang XH, Wei XH, Sang T, Zhao Q, Feng Q, Zhao Y, Li CY, Zhu CR, Lu TT, Zhang ZW, Li M, Fan DL, Guo YL, Wang AH, Wang L, Deng LW, Li WJ, Lu YQ, Weng QJ, Liu KY, Huang T, Zhou TY, Jing YF, Li W, Lin Z, Buckler ES, Qian Q, Zhang QF, Li JY, Han B (2010) Genome-wide association studies of 14 agronomic traits in rice landraces. Nat Genet 42:961-967

Huang XH, Zhao Y, Wei XH, Li CY, Wang AH, Zhao Q, Li WJ, Guo YL, Deng LW, Zhu CR, Fan DL, Lu YQ, Weng QJ, Liu KY, Zhou TY, Jing YF, Si LZ, Dong GJ, Huang T, Lu TT, Feng Q, Qian Q, Li JY, Han B (2012) Genome-wide association study of flowering time and grain yield traits in a worldwide collection of rice germplasm. Nat Genet 44:32-39

Ismail AM, Ella ES, Vergara GV, Mackill DJ (2009) Mechanisms associated with tolerance to flooding during germination and early seedling growth in rice (Oryza sativa). Ann Bot 103:197-209 
Itoh H, Tanaka-Ueguchi M, Kawaide H, Chen X, Kamiya Y, Matsuoka M (1999) The gene encoding tobacoo gibberellin 3-hyhydroxylase is expressed at the site of GA action during stem elongation and flower development. Plant J 20:15-24 Jeon JS, Jung KH, Kim HB, Suh JP, Khush GS (2011) Genetic and molecular insights into the enhancement of rice yield potential. J Plant Biol 54:1-9

Jiang L, Liu S, Hou M, Tang J, Chen L, Zhai H, Wan JM (2006) Analysis of QTLs for seed low temperature germinability and anoxia germinability in rice (Oryza sativa L.). Field Crop Res 98:68-75. https://doi.org/10.1016/j.fcr.2005.12.015

Kang HM, Sul JH, Service SK, Zaitlen NA, Kong SY, Freimer NB, Sabatti C, Eskin E (2010) Variance component model to account for sample structure in genome-wide association studies. Nat Genet 42:348-354

Kato-Noguchi H, Morokuma M (2007) Ethanolic fermentation and anoxia tolerance in four rice cultivars. J Plant Physiol 164:168-173. https://doi.org/10. 1016/j.jplph.2005.09.017

Kawahara Y, de la Bastide M, Hamilton JP, Kanamori H, McCombie WR, Ouyang S, Schwartz DC, Tanaka T, Wu JZ, Zhou SG, Childs KL, Davidson RM, Lin HN, Quesada-Ocampo L, Vaillancourt B, Sakai H, Lee SS, Kim J, Numa H, Itoh T, Buell CR, Matsumoto T (2013) Improvement of the Oryza sativa Nipponbare reference genome using next generation sequence and optical map data. Rice 6(1):4. https://doi.org/10.1186/1939-8433-6-4

Kretzschmar T, Pelayo MAF, Trijatmiko KR, Gabunada LFM, Alam R, Jimenez R, Mendioro MS, Loedin IHS, Sreenivasulu N, Serres JB, Ismail AM, Mackill DJ, Septiningsih EM (2015) A trehalose-6-phosphate phosphatase enhances anaerobic germination tolerance in rice. Nat Plants 1:15124. https://doi.org/ 10.1038/nplants.2015.124

Lasanthi-Kudahettige R, Magneschi L, Loreti E, Gonzali S, Licausi F, Novi G, Beretta O, Vitulli F, Alpi A, Perata P (2007) Transcript Profiling of the Anoxic Rice Coleoptile. Plant Physiol 144(1):218-231

Lee HS, Sasaki K, Kang JW, Sato T, Song WY, Ahn SN (2017) Mesocotyl elongation is essential for seedling emergence under deepseeding condition in rice. Rice 10:32. https://doi.org/10.1186/s12284-017-0173-2

Leung J, Giraudat J (1998) Abscisic acid signal transduction. Annu Rev Plant Physiol Plant Mol Biol. 49:199-222

Li G, Tai F-J, Zheng Y, Luo J, Gong S-Y, Zhang Z-T, Li X-B (2010) Two cotton Cys2/ His2-type zinc-finger proteins, GhDi19-1 and GhDi19-2, are involved in plant response to salt/drought stress and abscisic acid signaling. Plant Mol Biol 74(4-5):437-452

Li XB, Yan WG, Agrama H, Jia LM, Jackson A, Moldenhauer K, Yeater K, Anna M, Wu DX (2012) Unraveling the complex trait of harvest index with association mapping in rice (Oryza sativa L.). PLoS One 7:e29350

Librado P, Rozas J (2009) DnaSP v5: a software for comprehensive analysis of DNA polymorphism data. Bioinformatics 25:1451-1452. https://doi.org/10. 1093/bioinformatics/btp187

Lim MN, Lee SE, Yim HK, Kim JH, Yoon IS, Hwang YS (2013) Differential anoxic expression of sugar-regulated genes reveals diverse interactions between sugar and anaerobic signaling Systems in Rice. Mol Cell 36:169-176. https:// doi.org/10.1007/s10059-013-0152-4

Lippert C, Listgarten J, Liu Y, Kadie CM, Davidson Rl, Heckerman D (2011) Fast linear mixed models for genome-wide association studies. Nat Methods 8:833-835

Liu WX, Zhang FC, Zhang WZ, Song LF, Wu WH, Chen YF (2013) Arabidopsis Di19 functions as a transcription factor and modulates PR1, PR2, and PR5 expressions in response to drought stress. Mol Plant 6:1487-1502

Lo SF, Yang SY, Chen KT, Hsing YI, Zeevaart JA, Chen LJ, Yu SM (2008) A novel class of gibberellin 2-oxidases control semidwarfism, tillering, and root development in rice. Plant Cell 20:2603-2618. https://doi.org/10. 1105/tpc.108.060913

Lo SF, Ho THD, Liu YL, Jiang MJ, Hsieh KT, Chen KT, Lee MH, Chen CY, Huang TP, Mikiko K, Sakakibara H, Chen LJ, Yu SM (2017) Ectopic expression of specifific GA2 oxidase mutants promotes yield and stress tolerance in rice. Plant Biotechnol J 15(7):850-864

Magneschi L, Perata P (2009) Rice germination and seedling growth in the absence of oxygen. Ann Bot 103(2):181-196

Magneschi L, Kudahettige RL, Alpi A, Perata P (2009) Comparative analysis of anoxic coleoptile elongation in rice varieties: relationship between coleoptile length and carbohydrate levels, fermentative metabolism and anaerobic gene expression. Plant Biol 11:561-573. https://doi.org/10.1111/j.1438-8677. 2008.00150.x

Mahender A, Anandan A, Pradhan SK (2015) Early seedling vigour, an imperative trait for direct-seeded rice: an overview on physio-morphological parameters and molecular markers. Planta 241:1027-1050. https://doi.org/10.1007/ s00425-015-2273-9
Mayr C (2015) Evolution and biological roles of alternative 3' UTRs. Trends Cell Biol 26(3):227-237

McKenna A, Hanna M, Banks E, Sivachenko A, Cibulskis K, Kernytsky A, Garimella K, Altshuler D, Gabriel S, Daly M, DePristo MA (2010) The genome analysis toolkit: a MapReduce framework for analyzing next-generation DNA sequencing data. Genome Res 20:1297-1303

Miro B, Ismail AM (2013) Tolerance of anaerobic conditions caused by flooding during germination and early growth in rice (Oryza sativa L.). Front Plant Sci 4:269

Miro B, Longkumer T, Entila FD, Kohli A, Ismail AM (2017) Rice seed germination underwater: morpho-physiological responses and the bases of differential expression of alcoholic fermentation enzymes. Front Plant Sci 8:1857. https:// doi.org/10.3389/fpls.2017.01857

Mohanty B, Herath V, Wijaya E, Yeo HC, Reyes BG, Lee DY (2012) Patternsof ciselement enrichment reveal potential regulatory modules involved in the transcriptional regulation of anoxia response of japonica rice. Gene 511:235242. https://doi.org/10.1016/j.gene.2012.09.048

Nghi KN, Tondelli A, Valè G, Tagliani A, Marè C, Perata P, Pucciariello C (2019) Dissection of coleoptile elongation in japonica Rice under submergence through integrated genome-wide association mapping and transcriptional analyses. Plant Cell Environ 42:1832-1846. https://doi.org/ 10.1111/pce.13540

Nijhawan A, Jain M, Tyagi AK, Khurana JP (2008) Genomic survey and gene expression analysis of the basic leucine zipper transcription factor family in rice. Plant Physiol 146(2):333-350

Olszewski N, Sun TP, Gubler F (2002) Gibberellin signaling: biosynthesis, catabolism, and response pathways. Plant Cell 14(Suppl.):S61-S80

Pearce DME, Jackson MB (1991) Comparison of growth responses of barnyard grass (Echinochloa oryzoides) and rice (Oryza sativa) to submergence, ethylene, carbon-dioxide and oxygen shortage. Ann Bot 68:201-209

Perata P, Alpi A (1993) Plant responses to anaerobiosis. Plant Sci 93:1-17

Price AL, Patterson NJ, Plenge RM, Weinblatt ME, Shadick NA, Reich D (2006) Principal components analysis corrects for stratification in genome-wide association studies. Nat Genet 38:904-909

Purcell S, Neale B, Todd-Brown K, Thomas L, Ferreira MA, Bender D, Maller J, Sklar P, de Bakker PI, Daly MJ, Sham PC (2007) PLINK: a tool set for whole-genome association and population-based linkage analyses. Am J Hum Genet 81:559-575

Rieu I, Eriksson S, Powers SJ, Gong F, Griffiths J, Woolley L, Benlloch R, Nilsson O, Thomas SG, Hedden P, Phillipsa AL (2008) Genetic analysis reveals that $C_{19^{-}}$. GA 2-oxidation is a major gibberellin inactivation pathway in Arabidopsis. Plant Cell 20:2420-2436. https://doi.org/10.1105/tpc.108.058818

Robinson MD, McCarthy DJ, Smyth GK (2010) edgeR: a bioconductor package for differential expression analysis of digital gene expression data. Bioinformatics 26(1):139-140

Sakamoto T, Morinaka Y, Ishiyama K, Kobayashi M, Itoh H, Kayano T, Iwahori S, Matsuoka M, Tanaka H (2003) Genetic manipulation of gibberellin metabolism in transgenic rice. Nat Biotechnol 21(8):909-913

Schadel WE, Walter WM (1981) Localization of phenols and polyphenol oxidase in "Jewel" sweet potatoes (Ipomoea batatas "Jewel"). Can J Bot 59:1961-1967

Schomburg FM, Bizzell CM, Lee DJ, Zeevaart JAD, Amasino RM (2003) Over expression of a novel class of gibberellin 2-oxidases decreases gibberellin levels and creates dwarf plants. Plant Cell 15:151-163

Septiningsih EM, Ignacio JC, Sendon PM, Sanchez DL, Ismail AM, Mackill DJ (2013) QTL mapping and confirmation for tolerance of anaerobic conditions during germination derived from the rice landrace Ma-Zhan red. Theor Appl Genet 126:1357-1366. https://doi.org/10.1007/s00122-013-2057-1

Setter T, Ella ES (1994) Relationship between coleoptile elongation and alcoholic fermentation in rice exposed to anoxia. I. importance of treatment conditions and different tissues. Ann Bot 74:265-271. https://doi.org/10.1006/ anbo.1994.1117

Shingaki-Wells R, Millar AH, Whelan J, Narsai R (2014) What happens to plant mitochondria under low oxygen? An Omics review of the responses to low oxygen and Reoxygenation. Plant Cell Environ 37:2260-2277. https://doi.org/ 10.1111/pce.12312

Singh K, Kumar V, Saharawat YS, Gathala M, Ladha JK, Chauhan BS (2013) Weedy rice: an emerging threat for direct-seeded rice production systems in India. J Rice Res 1:106

Tamura K, Dudley J, Nei M, Kumar S (2007) MEGA4: molecular evolutionary genetics analysis (MEGA) software version 4.0. Mol Biol Evol 24:1596-1599. https://doi.org/10.1093/molbev/msm092

Trapnell C, Roberts A, Goff L, Pertea G, Kim D, Kelley DR, Pimentel H, Salzberg SL, Rinn JL, Pachter L (2012) Differential gene and transcript expression analysis of RNA-seq experiments with TopHat and cufflinks. Nat Protoc 7:562-578 
Wallner S, Dully C, Daniel B, Macheroux P (2013) In: Hille R, Miller SM, Palfrey B (eds) Handbook of Flavoproteins, Oxidases, Dehydrogenases and Related Systems, vol 1. De Gruyter, Berlin

Wang LL, Yu CC, Xu SL, Zhu YG, Huang WC (2016) OsDi19-4 acts downstream of OsCDPK14 to positively regulate ABA response in rice. Plant Cell Environ 39: 2740-2753

Wen ZX, Tan RJ, Yuan JZ, Bales C, Du WY, Zhang SZ, Chilvers MI, Schmidt C, Song QJ, Cregan PB, Wang D (2014) Genome-wide association mapping of quantitative resistance to sudden death syndrome in soybean. BMC Genomics 15:809. https://doi.org/10.1186/1471-2164-15-809

Winter D, Vinegar B, Nahal H, Ammar R, Wilson GV, Provart NJ (2007) An "electronic fluorescent pictograph" browser for exploring and analyzing large-scale biological data sets. PLoS One 2:e718. https://doi.org/10.1371/ journal.pone.0000718

Wu JH, Feng FJ, Lian XM, Teng XY, Wei HB, Yu HH, Xie WB, Yan M, Fan PQ, Li Y, Ma XS, Liu HY, Yu SB, Wang GW, Zhou FS, Luo LJ, Mei HW (2015) Genomewide association study (GWAS) of mesocotyl elongation based on resequencing approach in rice. BMC Plant Biol 15:218. https://doi.org/10.1186/ s12870-015-0608-0

Yamaguchi S (2008) Gibberellin metabolism and its regulation. Annu Rev Plant Biol 59:225-251

Yamaguchi S, Smith MW, Brown RG, Kamiya Y, Sun T (1998) Phytochrome regulation and differential expression of gibberellin 3beta-hydroxylase genes in germinating Arabidopsis seeds. Plant Cell 10:2115-2126

Yamauchi M, Aguilar AM, Vaughan DA, Seshu DV (1993) Rice (Oryza sativa L.) germplasm suitable for direct sowing under flooded soil surface. Euphytica 67:177-184

Yamauchi Y, Takeda-Kamiya N, Hanada A, Ogawa M, Kuwahara A, Seo M, Kamiya Y, Yamaguchi S (2007) Contribution of gibberellin deactivation by AtGA20x2 to the suppression of germination of dark-imbibed Arabidopsis thaliana seeds. Plant Cell Physiol 48:555-561

Yang W, Guo Z, Huang C, Duan L, Chen G, Jiang N, Fang W, Feng H, Xie W, Lian X, Wang GW, Luo QM, Zhang QF, Liu Q, Xiong LZ (2014) Combining highthroughput phenotyping and genome-wide association studies to reveal natural genetic variation in rice. Nat Commun 5:5087. https://doi.org/10. 1038/ncomms6087

Yang GL, Chen SP, Chen LK, Sun K, Huang CH, Zhou DH, Huang YT, Wang JF, Liu YZ, Wang H, Chen ZQ, Guo T (2019a) Development of a core SNP arrays based on the KASP method for molecular breeding of rice. Rice (N Y). 12(1): 21. https://doi.org/10.1186/s12284-019-0272-3

Yang J, Sun K, Li DX, Luo LX, Liu YZ, Huang M, Yang GL, Liu H, Wang H, Chen ZQ, Guo T (2019b) Identification of stable QTLs and candidate genes involved in anaerobic germination tolerance in rice via high-density genetic mapping and RNA-Seq. BMC Genomics 20(1):355. https://doi.org/10.1186/ s12864-019-5741-y

Yim HK, Lim MN, Lee SE, Lim J, Lee Y, Hwang YS (2012) Hexokinasemediated sugar signaling controls expression of the Calcineurin B-like interacting protein kinase 15 gene and is perturbed by oxidative phosphorylation inhibition. J Plant Physiol 169:1551-1558. https://doi.org/ 10.1016/j.jplph.2012.06.003

Yu HH, Xie WB, Li J, Zhou FS, Zhang QF (2014) A whole-genome SNP array (RICE6K) for genomic breeding in RICE. Plant Biotechnol J 12:28-37. https:// doi.org/10.1111/pbi.12113

Zhang MC, Lu Q, Wu W, Niu XJ, Wang CH, Feng Y, Xu Q, Wang S, YuanXP YHY, Wang YP, Wei XH (2017) Association mapping reveals novel genetic loci contributing to flooding tolerance during germination in indica rice. Front Plant Sci 8:678. https://doi.org/10.3389/fpls.2017.00678

Zhang P, Zhong KZ, Zhong ZZ, Tong HH (2019) Genome-wide association study of important agronomic traits within a core collection of rice (Oryza sativa L.). BMC Plant Biol 19:259. https://doi.org/10.1186/s12870-019-1842-7

Zhao KY, Tung CW, Eizenga GC, Wright MH, Liakat Ali M, Price AH, Norton GJ, Islam MR, Reynolds A, Mezey J, McClung AM, Bustamante CD, McCouch SR (2011) Genome-wide association mapping reveals a rich genetic architecture of complex traits in Oryza sativa. Nat Commun 2:467. https://doi.org/10.1038/ ncomms1467

Zou MJ, Guan YC, Ren HB, Zhang F, Chen F (2007) Characterization of alternative splicing products of bZIP transcription factors OSABI5. Biochem Biophys Res Commun 360(2):307-313

\section{Publisher's Note}

Springer Nature remains neutral with regard to jurisdictional claims in published maps and institutional affiliations.

\section{Submit your manuscript to a SpringerOpen ${ }^{\circ}$ journal and benefit from:}

- Convenient online submission

- Rigorous peer review

- Open access: articles freely available online

- High visibility within the field

- Retaining the copyright to your article

Submit your next manuscript at $\boldsymbol{\nabla}$ springeropen.com 